\title{
Research Trends of Metallic Sandwich Plates with Single Layer Periodically Repeated Metallic Inner Structures (PRMIS) - Focused on Design, Manufacturing and Formability
}

Dong-Gyu Ahn ${ }^{1, *}$

1 Department of Mechanical Engineering, Chosun University, 309, Pilmun-daero, Dong-gu, Gwangju, 61452, South Korea \# Corresponding Author / E-mail: smart@chosun.ar.kr, TEL: +82-62-230-7043, FAX: +82-62-230-7234

KEYWORDS: Metallic sandwich plate, Periodically repeated metallic inner structures (PRMIS), Single layer, Design, Manufacturing, Formability

\begin{abstract}
Recently, the attempt to decrease greenhouse gases, noxious gases and utilized energy sources has emerged as a crucial issue in the world to manage problems of global warming, resource depletion and air pollution. Institutes, universities and industries related to transport vehicles have endeavored to solve these crucial problems through the reduction of the overall weight of transport vehicles. However, the weight reduction of components of transport vehicles greatly affects the strength, the stiffness and the energy absorption of transport vehicles. Metallic sandwich plates with periodically repeated metallic inner structures (PRMIS) have been introduced to meet these conflicting demands. This paper reviews recent research trends of metallic sandwich plates with PRMIS in terms of design, manufacturing and formability. This paper is focused on a single layer PRMIS. Key technologies and the state-of-the art related to design, manufacturing and formability of metallic sandwich plates with PRMIS are discussed. In addition, future research issues of metallic sandwich plates with PRMIS are described.
\end{abstract}

Manuscript received: September 1, 2015 / Revised: September 8, 2015 / Accepted: September 15, 2015 (Invited Paper)

\section{NOMENCLATURE}

$\rho_{\mathrm{r}}=$ relative density

$\rho=$ density of the metallic sandwich plate with PRMIS

$\rho_{\mathrm{s}}=$ density of the monolithic material

$\mathrm{m}=$ mass of the metallic sandwich plate with PRMIS with identical volume to monolithic material

$\mathrm{m}_{\mathrm{s}}=$ mass of the monolithic material

$\varphi=$ flexural rigidity

$\mathrm{E}_{\mathrm{f}}=$ elastic modulus of a face sheet

$\mathrm{b}=$ width of the metallic sandwich plate

$\mathrm{n}=$ distance between neutral axes of face sheets

$t_{\mathrm{f}}=$ thickness of the face sheet

$\mathrm{E}_{\mathrm{c}}=$ elastic modulus of inner structures

$\mathrm{s}=$ thickness of inner structures

$\mathrm{D}_{\mathrm{i}}=$ diameter of strut and wire for unit inner structure
$\mathrm{L}_{\mathrm{i}}=$ length of strut, wire and edge for unit inner structure

$t_{i}=$ thickness of strut and edge for unit inner structure

$\theta_{\mathrm{i}}=$ included angle of unit inner structure

\section{Introduction}

Recently, the reduction of greenhouse gases, noxious gases and utilized energy sources has emerged as a crucial issue in the world to manage problems of global warming, resource depletion and air pollution. ${ }^{1-6}$ Institutes, universities and industries related to transport vehicles, including automotive, aircraft, the ship, space shuttle, rail vehicle, etc., have endeavored to solve these crucial problems through the reduction of the overall weight of transport vehicles. ${ }^{7-13}$ However, the weight reduction of components of transport vehicles greatly affects the strength, the stiffness and the energy absorption of the transport 


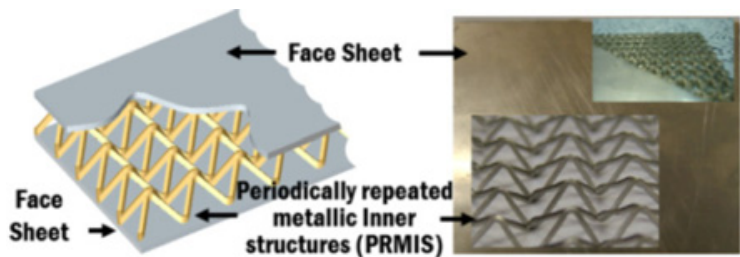

Fig. 1 Concept of metallic sandwich plates with PRMIS(example of pyramidal truss inner structures) ${ }^{28,29}$ (adapted from Refs. 28 and 29 with permission)

vehicle. $^{14-16}$ Metallic sandwich plates with periodically repeated metallic inner structures (PRMIS) have been introduced to meet these conflicting demands. ${ }^{17-27}$

$$
\rho_{r}=\frac{\rho}{\rho_{s}}=\frac{m}{m_{s}}
$$

Metallic sandwich plates consist of face sheets and inner structures with periodically repeated shapes, as shown in Fig. 1. ${ }^{17-23,25-28}$ The face sheets and the inner structures are created from metallic materials. ${ }^{17-}$ 23,25-28 An empty volume is formed in the core region with the metallic inner structures, as shown in Fig. 1..$^{17-23,25-29}$ The weight of a lightweight sandwich plate with PRMIS can be greatly smaller than that of a monolithic plate with an identical volume. ${ }^{18-22,30}$ The reduction of relative density of the plate is an important issue in the design of metallic sandwich plates. Eq. (1) represents the relative density of metallic sandwich plates. ${ }^{18-22,30}$ The specific stiffness and the specific energy absorption rate of a metallic sandwich plate with PRMIS are superior to those of a monolithic plate with identical volume and material. ${ }^{31-33}$ An attractive merit of metallic sandwich plates with PRMIS is that the weight, the structural properties and the functionality can be controlled by suitable design of the PRMIS and the face sheet. Due to above advantages, the academy and the industry have begun to pay attention to the importance of metallic sandwich plates with PRMIS.

This paper reviews recent research trends of metallic sandwich plates with single layer PRMIS in terms of design, manufacturing and formability. This paper is focused on a single layer PRMIS. Key technologies and the state-of-the art related to design, manufacturing and formability of metallic sandwich plates with PRMIS are discussed. Finally, future research issues for metallic sandwich plates with PRMIS are described.

\section{Metallic Sandwich Plates with Single Layer PRMIS}

Fig. 2 illustrates schematics and sectional dimensions of a metallic sandwich plate with single layer PRMIS. ${ }^{34-36}$ The flexural rigidity $(\varphi)$ is represented by Eq. (2). The first term and the third term of Eq. (2) are the local stiffness of the face sheets and the bending stiffness of inner structures, respectively. ${ }^{34-36}$ In case design conditions of a metallic sandwich plate satisfy Eqs. (3) and (4), the effects of the local stiffness of face sheets and the bending stiffness of inner structures on the flexural rigidity of the metallic sandwich plate with PRMIS can be disregarded. ${ }^{34-36}$ In this paper, metallic sandwich plates are classified into thick and thin metallic sandwich plates according to the combination of the thickness of the face sheet and the thickness of the inner structure. The combination of thicknesses of the face sheet and

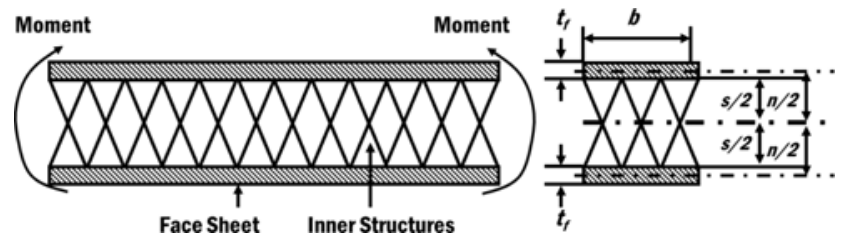

Fig. 2 Schematics of sectional dimensions of metallic sandwich plates with single layer PRMIS ${ }^{34-36}$

Table 1 Metallic sandwich plates and single layer periodically repeated metallic inner structures (PRMIS) ${ }^{17-23,26,28-33,35-57,61-72}$

\begin{tabular}{|c|c|c|}
\hline \multirow{2}{*}{$\begin{array}{l}\text { Type of } \\
\text { plate }\end{array}$} & \multicolumn{2}{|c|}{ PRMIS (Single layer) } \\
\hline & Shape & Material \\
\hline \multirow{8}{*}{ Thick } & $\begin{array}{l}\text { Pyramidal truss } \\
21,27,33,37-40\end{array}$ & $\begin{array}{c}\text { Stainless steel (304, AL-6XBN), } \\
\text { Aluminum alloy (AA3003, AA4343, } \\
\text { AA6951) }\end{array}$ \\
\hline & Tetrahedral truss & Stainless steel (304), \\
\hline & $19-21,31,37,38,41-43$ & Aluminum alloy, Copper/Beryllium \\
\hline & $\begin{array}{c}\text { Kagome } \\
21,27,37,38,43-46\end{array}$ & $\begin{array}{c}\text { Copper/Beryllium, Mild steel, } \\
\text { Stainless steel, Cr-Si spring steel, } \\
\text { Tungsten }\end{array}$ \\
\hline & $\begin{array}{c}\text { Woven wire } \\
18,20,21,27,37,47-49\end{array}$ & Stainless steel \\
\hline & $\begin{array}{c}\text { Honeycomb } \\
17-19,21,32,37,50-53\end{array}$ & Stainless steel (304), Aluminum \\
\hline & $\begin{array}{l}\text { Uni-Directionally } \\
\text { corrugate } \\
21-23,37,51,53-55 \\
\end{array}$ & Stainless steel (304), Al6061 T6 \\
\hline & Y-Frame ${ }^{23,56,57}$ & Stainless steel (304) \\
\hline \multirow{5}{*}{ Thin } & $\begin{array}{c}\text { Pyramidal truss } \\
26,28-30,36,65,66,71\end{array}$ & Mild steel \\
\hline & Woven wire ${ }^{30,35}$ & Stainless steel \\
\hline & Dimple ${ }^{63,64,67}$ & Stainless steel (304) \\
\hline & $\begin{array}{l}\text { Sheared dimple } \\
61,62,68,70-72\end{array}$ & Mild steel \\
\hline & $\begin{array}{c}\text { Bi-Directionally } \\
\text { corrugate }^{69}\end{array}$ & Mild steel \\
\hline
\end{tabular}

that of the inner structure for thick metallic sandwich plates should satisfy Eqs. (3) and (4) together. ${ }^{34-36}$

$$
\begin{gathered}
\varphi=E_{f} \frac{b t_{f}^{3}}{6}+E_{f} \frac{b t_{f} n^{2}}{2}+E_{c} \frac{b s^{3}}{12} \\
3\left(\frac{n}{t_{f}}\right)^{2}>100 \text { or } \frac{n}{t_{f}}>5.77 \\
0.02<\frac{t_{f}}{s}<0.1 \text { and } \frac{n}{s} \cong 1.0
\end{gathered}
$$

However, thin metallic sandwich plate does not satisfy Eqs. (3) or (4)..$^{35,36}$

Various types of single layer PRMIS were developed for the thick metallic sandwich plates, as shown in Table 1 and Fig. 3. ${ }^{17-23,31-33,37-57}$ Table 2 summarizes the relative density of reference shapes of PRMIS for thick metallic sandwich plates.

The pyramidal truss, the tetrahedral truss and the Kagome was been widely used as truss types of PRMIS. ${ }^{19-21,27,31,33,37-46}$ Truss type PRMIS have the largest empty volume in the core region among type PRMIS. Therefore, the truss type PRMIS can greatly reduce the relative density of the metallic sandwich plate. Relative densities of pyramidal and 


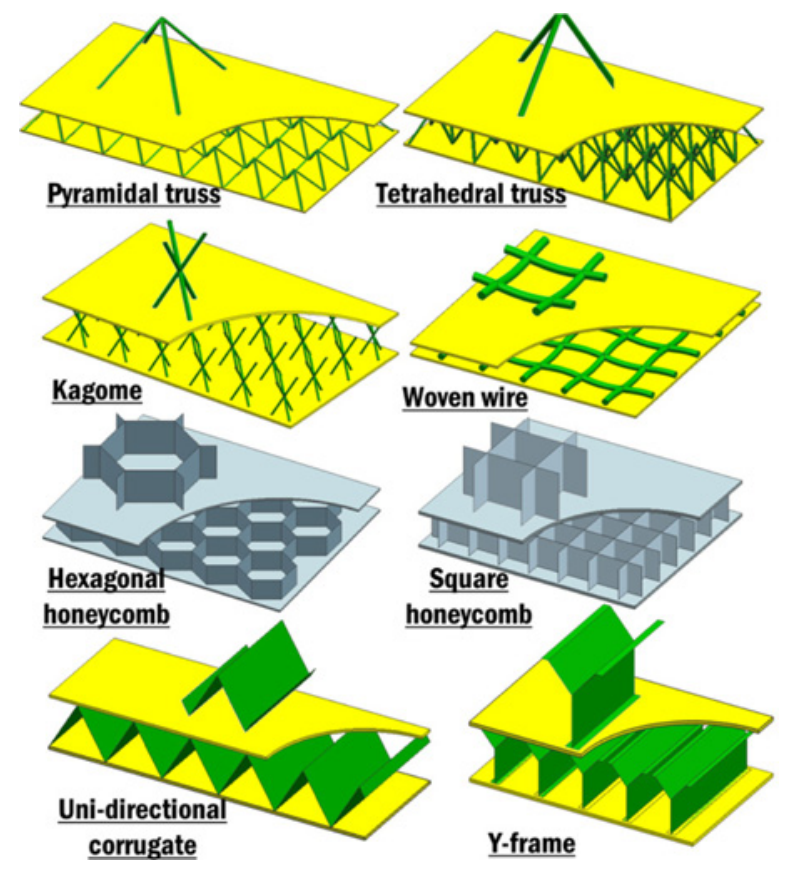

Fig. 3 Schematics of metallic sandwich plates with PRMIS ${ }^{17,18,20-22,37}$ (adapted from Refs. 17, 18, 20-22 and 37)

Table 2 Relative density of reference shapes of the PRMIS for the thick metallic sandwich plate $\mathrm{e}^{19,21,22,27,32,37-39,43,45,46,48,50,56,57}$

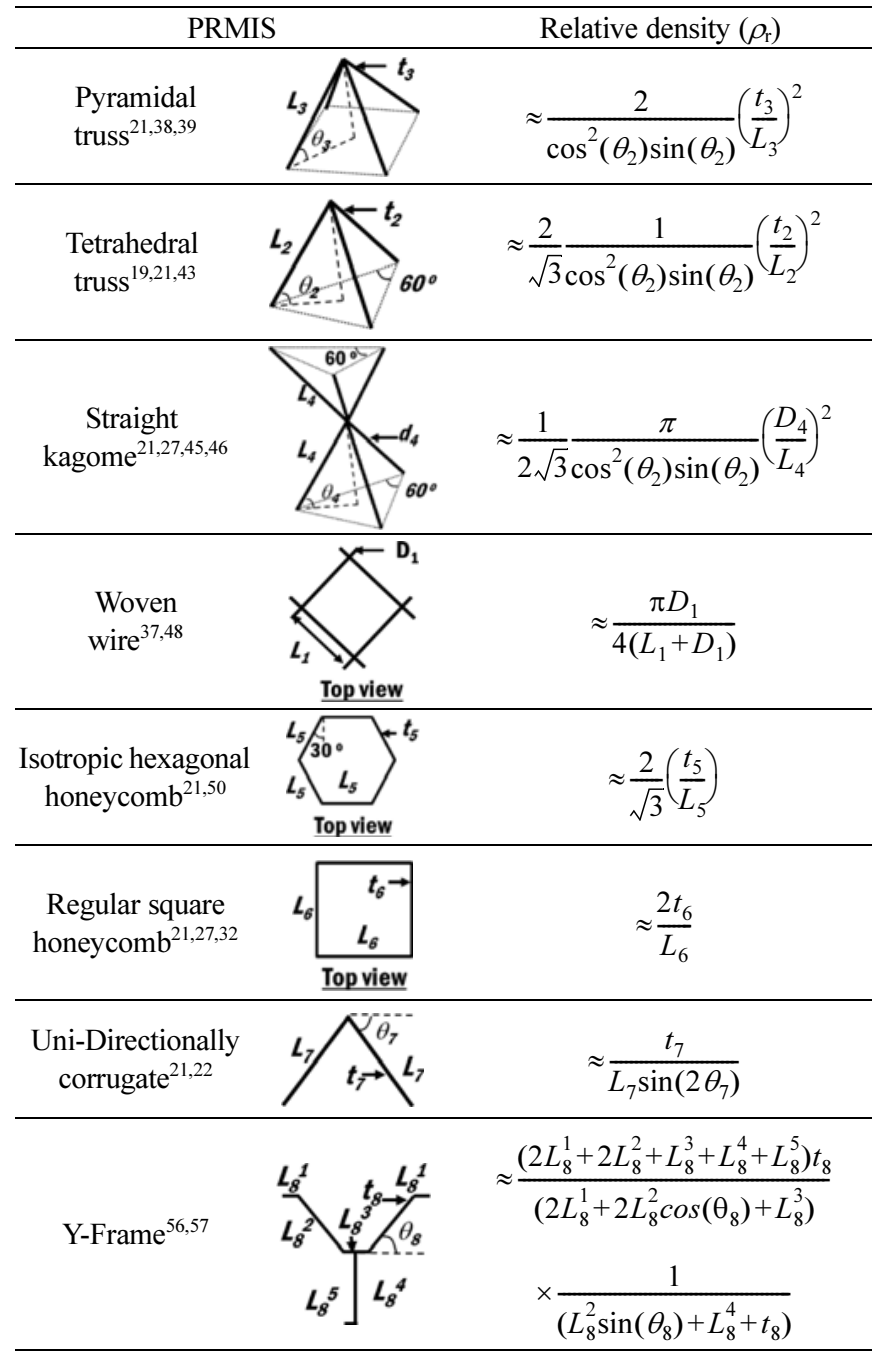

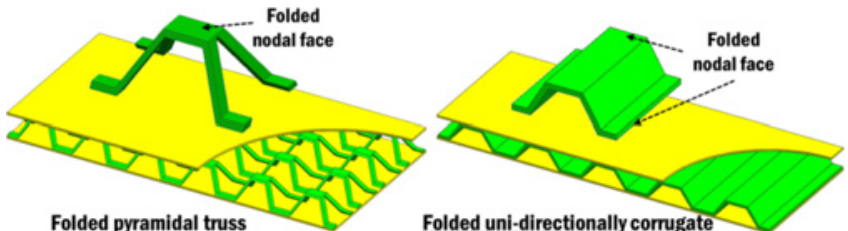

Fig. 4 Concept of folded pyramidal truss and folded corrugated inner structures $^{21,38,58}$ (adapted from Refs. 21, 38 and 58)

tetrahedral truss inner structures are influenced by the thickness, the length and the included angle of struts of the inner structure, as shown in Table 3. ${ }^{19,21,27,35,38}$ The relative density of the Kagome inner structure is dependent on the diameter, the half-length and the included angle of struts of the inner structure, as shown in Table $2 .^{21,27,45,46}$ Pyramidal truss inner structures were made from stainless steels (304 and AL6XBN) and aluminum alloys (AA3003, AA4343 and AA6951), as shown in Table $1 .^{27,33,37-40} 304$ stainless steel, aluminum alloy and copper/beryllium were used as materials of the tetrahedral truss inner structures. ${ }^{19,20,41-43}$ The Kagome inner structures were made from various metallic materials including copper-beryllium, mild steel, stainless steel, Cr-Si spring steel, tungsten, etc... 27,37,44,45

The woven wire inner structures was generally used as single layered textile inner structures..$^{18,20,21,27,37,47-49}$ The woven wire inner structures can enhance the specific stiffness. The woven wire was made from a stainless steel. ${ }^{37,48}$ The relative density of the woven wire inner structure is linearly proportional to the ratio of the diameter of the wire to the length of the wire, as shown in Table 3. ${ }^{37,48}$

Honeycomb, corrugate and Y-frame inner structures were designed to improve the out-of-plane performance of the metallic sandwich plate. $22,23,32,33,37,50-57$ The joined region between the face sheet and the PRMIS was changed to lines when honeycomb, corrugate and Y-frame inner structures was adopted, while the joined region was made of points when the truss type inner structures were used. Hence, the resistance to the face buckling of the metallic sandwich plate was improved when the honeycomb, corrugate and Y-frame inner structures were applied. Honeycomb inner structures with square and hexagonal shapes were designed to improve out-of-plane compressive, impact and shear characteristics. ${ }^{17-19,21,32,37,50-53}$ The relative densities of regular hexagonal and square honeycombs are in proportion to the ratio of the wall thickness to the length of unit inner structure, as shown in Table 2..$^{21,27,32,50}$ Honeycomb inner structures was made from an aluminum alloy and a stainless steel. ${ }^{32,37,52,53}$ Corrugated and Y-frame inner structures were contrived to improve the impact resistance. ${ }^{21-23,37,51,53-57}$ Anisotropic characteristics of the metallic sandwich plate appeared when uni-directionally corrugated and Y-frame inner structures were adopted. ${ }^{34,55}$ Folded regions were created in the vicinity of edges of the Y-frame inner structure, as shown in Fig. 3. ${ }^{23,56,57}$ The folded regions of the Y-frame inner structures improved the joining characteristics between the face sheet and the Y-frame inner structures. ${ }^{23,56,57}$

Several researchers designed folded pyramidal truss inner structures with flat nodal regions and fold corrugated inner structures to improve joining characteristics between the face sheet and the inner structures, as shown in Fig. 4. ${ }^{21,38,58}$ The widened joined region between the inner structures and the face sheets can enhance the resistance to face buckling of the metallic sandwich plate. 


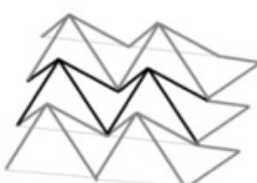

Pyramidal truss

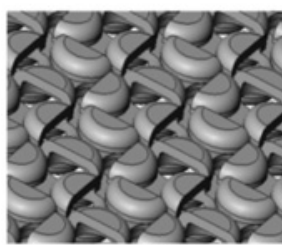

Sheared Dimple

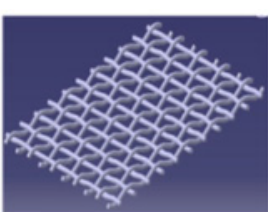

Woven wire

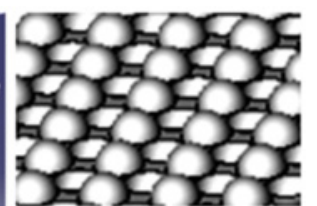

Dimple

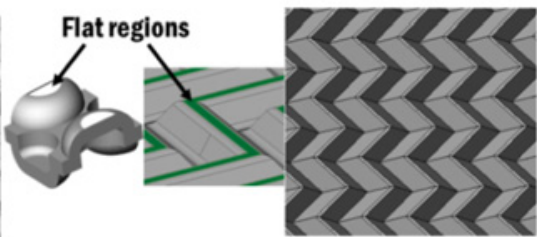

Bi-directionally corrugated
Fig. 5 Examples of the PRMIS for thin metallic sandwich plates $^{29,63,71,72}$ (adapted from Refs. 29, 63, 71 and 72 with permission of Prof. Dong-Yol Yang, Dr. Chang-Gyun Jung and Dr. Dae-Yong Seong)

In general, the material of the face sheets was almost identical to that of the PRMIS excluding the Kagome inner structures. In case of the Kagome inner structures, a copper-beryllium, a mild steel and a stainless steel were adopted as the material of the face sheets..$^{27,38,43-46}$

Due to the formability problem of thick metallic sandwich plates, the application of thick metallic sandwich plates to parts of transport vehicles was limited. ${ }^{26,29,59-62}$ Yang et al. developed a thin metallic sandwich plate with PRMIS to improve the deformation characteristics and the formability of metallic sandwich plates. ${ }^{26,28-30,35,36,61-72}$ The thickness of the thin metallic sandwich plates was less than $3 \mathrm{~mm} \cdot{ }^{26,28-}$ 30,35-36,61-72 Thin metallic sandwich plates were employed for five types of inner structures, as shown in Table 2 and Fig. 5. 26,28-30,35-36,61-72

The pyramidal truss, woven wire and dimple types of PRMIS were designed to apply thin metallic sandwich plates to components with large radius of curvature of the forming die..$^{26,28-30,35,36,63-67,71}$ Sheared dimple and bi-directional corrugated inner structures were contrived to greatly improve the formability and the out-of-plane performance of the metallic sandwich plate through the improvement of the resistance to face wrinkling and core shear..$^{61,62,68-73}$ The bi-directionally corrugated inner structures led to the improvement of anisotropic characteristics of uni-directionally corrugated inner structures. ${ }^{69}$ In order to improve the resistance to face buckling and joining characteristics between the face sheets and inner structures, flat regions were created in the vicinity of node regions of the sheared dimple and the bi-directionally corrugated inner structures, as shown in Fig. 5. ${ }^{61,62,68-72}$ Metallic sandwich plates with sheared dimple and bidirectionally corrugated inner structures can be applicable to forming of parts with a small radius of curvature of the forming die. ${ }^{61,68,71,72}$

Pyramidal truss, sheared dimple and bi-directionally corrugated inner structures were made from a mild steel..$^{30,35,63,64,67,68}$ Stainless steel was used to create woven wire and dimple inner structures. The thickness of the face sheets for the thin metallic sandwich plates ranged from $0.27 \mathrm{~mm}$ to $0.3 \mathrm{~mm}$. 304 stainless steel was generally utilized as the material for the face sheets for the thin metallic sandwich plates. $^{30,35,63,66,69-71}$ In case of the sheared dimple inner structure, 590 dual phase (DP) steel and 304 stainless steel were used to create the face sheets. ${ }^{61,62,68,70-72}$ Mild steel was utilized as the face sheet material of the bi-directionally corrugated inner structures. ${ }^{68}$

\section{Fabrication Methodologies of Metallic Sandwich Plates with Single Layer PRMIS}

In order to fabricate metallic sandwich plates with PRMIS, two manufacturing sequences, including manufacturing of PRMIS and joining of PRMIS to the face sheets, were needed. Various fabrication methodologies of metallic sandwich plates with PRMIS were proposed for different types of PRMIS, as shown in Table 3.

\subsection{Thick Metallic Sandwich Plate}

Thick metallic sandwich plates with pyramidal truss inner structures were fabricated from four types of manufacturing technology, as shown in Table 3..$^{21,33,37-40,73-76}$ In manufacturing technologies of thick metallic sandwich plates with pyramidal truss inner structures using the perforated sheet, the elongated diamond perforated sheet was manufactured from successive laser cutting and die punching processes, as described by Fleck and Wadely et al. ${ }^{21,33,37-39,73-75}$ Subsequently, rows of the elongated diamond perforated sheet were bent by the crimping process..$^{21,33,37-39,73-75}$ Through the repetition of these processes, pyramidal truss inner structures were created. ${ }^{21,33,37-}$ ${ }^{39,73-75}$ Face sheets and pyramidal truss inner structures were joined by brazing and laser spot welding processes. ${ }^{21,33,37-38,73-76}$ Several researchers used $\mathrm{Ni}-25 \mathrm{Cr}-10 \mathrm{P}, \mathrm{Ni}-22 \mathrm{Cr}-6.5 \mathrm{Si}-4.5 \mathrm{P}$ and polymer-based cement to perform the vacuum brazing process in an argon environment. . $^{21,33,37-38,73-75}$ Yungwirth et al. employed the laser spot welding process for joining the face sheets and the pyramidal truss inner structures. ${ }^{76}$ The perforation of the metal sheet, which is fabricated from laser cutting and die punching processes, created a considerable amount of the wasted material from the original metal sheet. $^{21,38}$ Wadley et al. developed a novel perforation process using slitting, expanding and roll flattening processes, as shown in Fig. 6(a). ${ }^{21,38}$ The slitting and expanding processes greatly reduced an amount of the wasted material during the perforation process. ${ }^{21,38}$ They also proposed a folding process, in which bending of the perforated sheet and flattening of nodal region were performed, to create pyramidal truss inner structures with flat nodal regions. ${ }^{21,38}$ These structures were joined to the face via a brazing process. ${ }^{21,38}$ Several researchers reported that imperfections of the inner structures and joined regions affect characteristics of metallic sandwich plates with pyramidal truss inner structures. ${ }^{39,77}$ Biagi and Bart-Smith investigated into the influence of de-bonding imperfections between face sheets and pyramidal truss inner structures on compressive and shear responses of the metallic sandwich plates with pyramidal truss inner structures. ${ }^{39}$ Lee et al. examined the effects of strut imperfections of the pyramidal truss inner structures on the impact response of the metallic sandwich plates. ${ }^{77}$ Queheillalt et al. manufactured integrated metallic sandwich plates with pyramidal truss inner structures from extrusion and electrical discharge machining (EDM) processes, as shown in Fig. 6 (b). ${ }^{40,66}$ They removed the joining process via manufacturing of the integrated metallic sandwich plates. ${ }^{40}$ An aluminum corrugated sandwich structure was created using an extrusion process in the heated environment. ${ }^{40}$ The EDM process was applied to cut-out the material of the side wall of the aluminum corrugated sandwich structure. ${ }^{40}$

Thick metallic sandwich plates with tetrahedral truss inner structures were manufactured from two types of fabrication technology, 
Table 3 Fabrication methodologies of metallic sandwich plates with single layer PRMIS ${ }^{19-21,23,26-30,32,33,35-49,52,54,56,58,61-65,67,69-76,78-97,99,100}$

\begin{tabular}{|c|c|c|c|}
\hline \multicolumn{2}{|c|}{ Sandwich plate } & \multicolumn{2}{|l|}{ Fabrication methodologies } \\
\hline Type & PRMIS & PRMIS & Joining \\
\hline \multirow{16}{*}{ Thick } & \multirow{4}{*}{$\underset{21,33,37-40,73-76}{\text { Pyramidal truss }}$} & Perforation(Laser cutting \& Die punching)-Elongation-Crimping & Brazing \\
\hline & & Perforation(Die punching)-Elongation-Crimping & Laser spot welding \\
\hline & & Slitting/expanding-Roll flattening-Folding(including node folding) & Brazing \\
\hline & & Extrusion-EDM cutting & - \\
\hline & \multirow[t]{2}{*}{$\begin{array}{l}\text { Tetrahedral truss } \\
19-21,37,38,41-43,78,79\end{array}$} & $\begin{array}{l}\text { Pattern fabrication (Injection moulding \& Rapid prototyping)-Investment } \\
\text { casting }\end{array}$ & - \\
\hline & & Perforation(Die punching)-Elongation-Crimping & Brazing, TLP bonding \\
\hline & \multirow{2}{*}{$\begin{array}{c}\text { Kagome } \\
21,27,37,44-46,80-83\end{array}$} & Rapid prototyping-Investment casting & - \\
\hline & & Weaving-Assemble & Soldering, Brazing, TLP bonding \\
\hline & \multirow{2}{*}{$\begin{array}{l}\text { Woven wire } \\
20,21,27,37,47-49\end{array}$} & Wire forming-Weaving & CDR welding \\
\hline & & Weaving & Brazing, TLP bonding \\
\hline & \multirow{3}{*}{$\begin{array}{c}\text { Honeycomb } \\
21,32,37,52,73,84,85\end{array}$} & $\begin{array}{l}\text { Hexagonal: Sheet cutting-Bending-Stacking \& Joining(Creation of HOBE, } \\
\text { Adhesive bonding \& Laser welding)-Slicing -Expansion }\end{array}$ & Adhesive bonding \\
\hline & & $\begin{array}{c}\text { Hexagonal: Corrugation-Stacking-Joining(Creation of the corrugated block, } \\
\text { Adhesive bonding \& Welding)-Slicing }\end{array}$ & Adhesive bonding \\
\hline & & $\begin{array}{l}\text { Square: Cropping (Conventional \& Laser sheet cutting)-Slotting(EDM \& } \\
\text { Laser cutting)-Assemble-Brazing of the assembled member }\end{array}$ & Brazing \\
\hline & \multirow{2}{*}{$\begin{array}{c}\text { Corrugate }_{4,56,58,86-88}^{21,23,33,40,5} \\
\end{array}$} & Cold folding using die (including node folding) & Brazing, Laser welding(Two steps) \\
\hline & & Extrusion- Friction stirring welding(Expansion in the width direction) & - \\
\hline & Y-Frame $e^{23,56,86,89}$ & $\begin{array}{l}\text { Step 1(Creation of web): Cold folding-CNC cutting, } \\
\text { Step 2(Creation of leg): Cold folding -CNC cutting, } \\
\text { Step 3(Assemble of web and leg): Brazing or Laser welding }\end{array}$ & $\begin{array}{c}\text { Brazing, } \\
\text { Laser welding(Two steps) }\end{array}$ \\
\hline \multirow{5}{*}{ Thin } & $\begin{array}{l}\text { Pyramidal truss } \\
26,28-30,36,65,71,90-92\end{array}$ & Slitting-Expanding \& Crimping (including node folding) & $\begin{array}{c}\text { Adhesive bonding, Multi-Points projection } \\
\text { welding (Including continuous welding), } \\
\text { Brazing }\end{array}$ \\
\hline & $\begin{array}{l}\text { Woven wire } \\
30,35,93-97\end{array}$ & Using commercialized woven wire & $\begin{array}{l}\text { Brazing, Adhesive bonding, Multi-Points } \\
\text { projection welding (Including continuous } \\
\text { welding) }\end{array}$ \\
\hline & Dimple $^{63,64,67}$ & Piecewise sectional forming & Multi-Points projection welding \\
\hline & $\underset{61,62,70-72,99}{\text { Sheared dimple }}$ & Continuous sectional forming, Roll forming & $\begin{array}{l}\text { Multi-Points projection welding (Including } \\
\text { continuous welding), Brazing }\end{array}$ \\
\hline & $\begin{array}{l}\text { Bi-Directional } \\
\text { corrugate }^{69,100}\end{array}$ & Piecewise sectional forming & Adhesive bonding \\
\hline
\end{tabular}

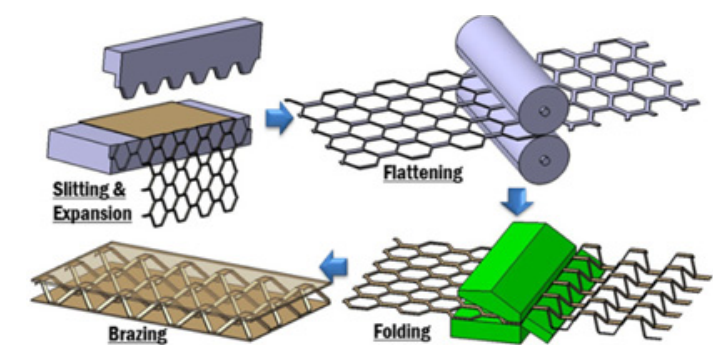

(a)

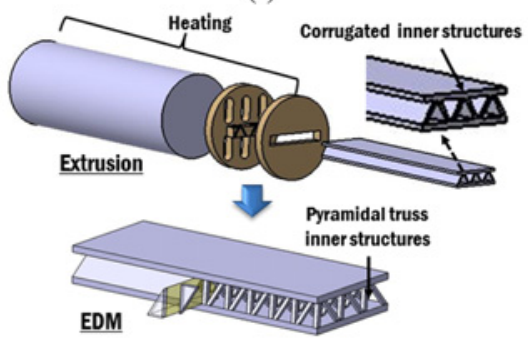

(b)

Fig. 6 Schematics of manufacturing processes for thick metallic sandwich plates with pyramidal truss inner structures; (a) Slitting/ expanding, flattening and folding based approach ${ }^{21,38}$ (adapted from Refs. 21 and 38) (b) Extrusion and EDM based approach ${ }^{40}$ (adapted from Ref. 40) as shown in Table 3. In the early stage, the manufacturing technology consisted of pattern fabrication and investment casting processes was used to fabricate integrated metallic sandwich plates with tetrahedral truss inner structures. ${ }^{21,37,41,42,78}$ Deshpande and Fleck manufactured patterns of tetrahedral truss inner structures from an injection moulding process of a polystyrene..$^{21,37,78}$ Patterns of thick metallic sandwich plates were created by joining of polystyrene tetrahedral truss inner structures and the polystyrene face sheets. ${ }^{78}$

Finally, thick metallic sandwich plates with tetrahedral truss inner structures were manufactured from an investment casting process with polystyrene patterns. ${ }^{78}$ Chiras et al. employed a rapid prototyping process for the fabrication of patterns of sandwich plates with tetrahedral truss inner structures. ${ }^{21,37,41,42}$ They used a fused deposition manufacturing (FDM) process to manufacture the ABS pattern. ${ }^{41,42}$ They also utilized the investment casting process to fabricate $\mathrm{Cu}-\mathrm{Be}$ and aluminum alloy sandwich plates with tetrahedral truss inner structures. ${ }^{41,42}$ Several researchers reported that various voids and cavities occur in the vicinity of face sheets, struts and intersection regions between face sheets and struts of cast metallic sandwich plates. ${ }^{21,41-43}$ In addition, Wadley reported that the investment casting process is difficult to create high aspect ratio channels and inner structures with low relative density. ${ }^{21}$ In order to overcome demerits of 
cast metallic sandwich plates with tetrahedral truss inner structures, another fabrication methodology using cold forming and joining processes was adopted, as shown in Table 3. ${ }^{19-21,37,38,79}$ Tetrahedral truss inner structures were manufactured from perforation of the metal sheet, elongation of the perforated sheet and crimping of the elongatedperforated sheet. ${ }^{19-21,37,38,79}$ Hexagonal perforated metal sheets were created using a die punching process, unlike the case of pyramidal truss inner structures. ${ }^{19,-21,37} \mathrm{~A}$ die set was employed for crimping of the elongated hexagonal perforated sheet. ${ }^{19-21,37}$ In general, two types of joining technology, including brazing and transient liquid phase (TLP) bonding processes, were used to bond the tetrahedral truss inner structures to the face sheets. ${ }^{19-21,37,38,79}$ The brazing process was applied when metallic sandwich plates were made from aluminum alloys, while the TLP bonding process was adopted when metallic sandwich plates were made from stainless steels. ${ }^{19-21,37,38,79}$ Sypeck et al. fabricated metallic sandwich plates with tetrahedral truss inner structures via brazing and TLP bonding processes. ${ }^{19-20}$ They used a spray consisting of the mixture of polymer based cement and Ni-25Cr-10P braze powder to apply the TLP bonding process. ${ }^{19}$ They also utilized both solid sheets and perforated sheets as face sheets of tetrahedral truss inner structures. ${ }^{19,20}$

Various methodologies for the fabrication of thick metallic sandwich plates with Kagome inner structures were developed, as shown in Table 3. Wang et al. manufactured integrated thick metallic sandwich plates with Kagome inner structures from FDM rapid prototyping and investment casting processes..$^{21,37,44}$ They reported that porosities occur in cast thick metallic sandwich plates. In most of the literature related to thick metallic sandwich plates with Kagome inner structures, these structures were fabricated from weaving of twisted wire and assembly of the woven wire. ${ }^{21,27,37,45,46,80-83}$ Kang et al. created Kagome inner structures using tri-axial weaving technology of the bent helical wire. ${ }^{27,46,80-82}$ They reported that joining of crossing points of struts and intersection regions between face sheets and Kagome inner structures was needed to fabricate thick metallic sandwich plates with Kagome inner structures..$^{27,46,80-82}$ They used soldering, brazing and TLP bonding processes to join all crossing points and intersection regions. ${ }^{27,46,80-82}$ Kang et al. fabricated perforated sheets from laser cutting process and solid sheets as the face sheet..$^{27,46,80-82}$ Hyun et al. investigated into the influence of imperfections, including geometrical imperfections of struts, imperfections of material properties and imperfections of brazing in the crossing points of struts, on the mechanical behavior of metallic sandwich plates with Kagome inner structures. ${ }^{81,82} \mathrm{Lim}$ et al. fabricated quasi-Kagome structures from bending of expanded metal sheets and folding of center struts of bent unit cells. ${ }^{83}$ They employed a brazing process for joining the Kagome inner structures to the face sheets. ${ }^{83}$ Kang critically reviewed fabrication methodologies of various types of Kagome inner structures. ${ }^{27}$ Kang investigated into procedures of the thick metallic sandwich plate with Kagome inner structures. ${ }^{27}$ Kang reported that brazing and soldering processes can be used to mass-produce thick metallic sandwich plates with Kagome inner structures. ${ }^{27} \mathrm{He}$ also reported that the TLP bonding process using an Ni alloy filler metal is suitable for the fabrication of metallic sandwich plates with stainless steels and high temperature materials. ${ }^{27}$

Thick metallic sandwich plates with woven wire inner structures were fabricated using two types of manufacturing technology, as shown in Table $3 .^{20,21,27,37,47-49}$ Dilthey et al. fabricated woven wire inner structures from the wire manufacturing process, including multi-steps drawing, copper coating, heat treatment and spooling, and the weaving process. ${ }^{47}$ The woven wire inner structures were joined to the perforated face sheet using the capacitor discharge resistance (CDR) welding process. ${ }^{47}$ They investigated into the influence of welding parameters of the CDR welding process on the quality of the welded region. ${ }^{47}$ The perforated face sheets were created using the laser drilling process. ${ }^{47}$ Several researchers used commercialized woven wires to fabricate the inner structures..$^{20,37,48,49}$ They employed TLP bonding and brazing processes for joining the woven wire inner structures to the face sheets. ${ }^{20,37,48,49}$ However, most of the research works related to manufacturing of thick metallic sandwich plates was focused on multilayered woven wire inner structures. ${ }^{20,21,37,48,49}$

Honeycomb inner structures were fabricated from various manufacturing processes..$^{21,32,37,52,73,84,85}$ Bitzer and Wadley et al. introduced two types of manufacturing process, including the expanded honeycomb manufacturing process and the corrugated honeycomb manufacturing process, for hexagonal honeycomb inner structures, as shown in Table 3..$^{21,37,84}$ The expanded honeycomb manufacturing process consisted of five sub-steps, as followings: (a) cutting of a metal sheet, (b) bending of the cut sheet, (c) creation of honeycomb before expansion (HOBE) block through stacking of the bent sheet and joining of stacked sheets, (d) slicing of HOBE, and (e) expansion of the sliced HOBE. ${ }^{21,85}$ In the joining of the stacked sheets, laser welding and adhesive bonding processes were adopted. ${ }^{21,85}$ The corrugated honeycomb manufacturing process was composed of four sub-steps, as followings: (a) corrugation of a metal sheet using a gear press, (b) stacking of the corrugated sheet, (c) creation of a corrugated block by joining of corrugated sheets, and (d) slicing of the corrugated block. ${ }^{21,85}$ The adhesive bonding and welding processes were employed for the corrugated sheets. The adhesive bonding process was used to join expanded and corrugated honeycomb inner structures to face sheets. ${ }^{37,84}$ Square-honeycomb inner structures were manufactured from the slotted metal sheet assembly process, as shown in Table 3. . $1,32,52,73,85$ The slotted metal sheet assembly process consisted of four sub-steps, as followings: (a) cropping of a metal sheet, (b) slotting of the cropped sheet, (c) assembly of the cropped sheet using the slots, and (d) joining of the assembled square honeycomb. ${ }^{21,32,52,73,85}$ Cote et al. developed manufacturing technology based on the slotted metal sheet assembly process to create square honeycomb inner structures. ${ }^{32,52,73}$ They employed electro-discharge machining (EDM) and brazing processes for the creation of cross-slots and fixation of the members of the inner structures, respectively. ${ }^{32,52,73}$ Dharmasena et al. applied a laser cutting process to the creation of cropped sheets with cross-slots and notches, as shown in Fig. 7(a). ${ }^{85}$ They created bend tabs on top and bottom flanges of the cropped sheet to increase joining regions between face sheets and honeycomb inner structures. ${ }^{85} \mathrm{~A}$ brazing process was used to join the square honeycomb inner structures to the face sheets. ${ }^{32,52,73,85} \mathrm{Ni}-25 \mathrm{Cr}-10 \mathrm{P}, \mathrm{Ni}-22 \mathrm{Cr}-6.5 \mathrm{Si}-4.5 \mathrm{P}$ and polymer-based cement were applied to the brazing process. ${ }^{32,52,73,85}$

Corrugated inner structures were fabricated from cold folding and extrusion processes, as shown in Table $3 .^{21,23,33,40,54,56,58,86-88}$ In the cold folding approach, the corrugated inner structures were generally 


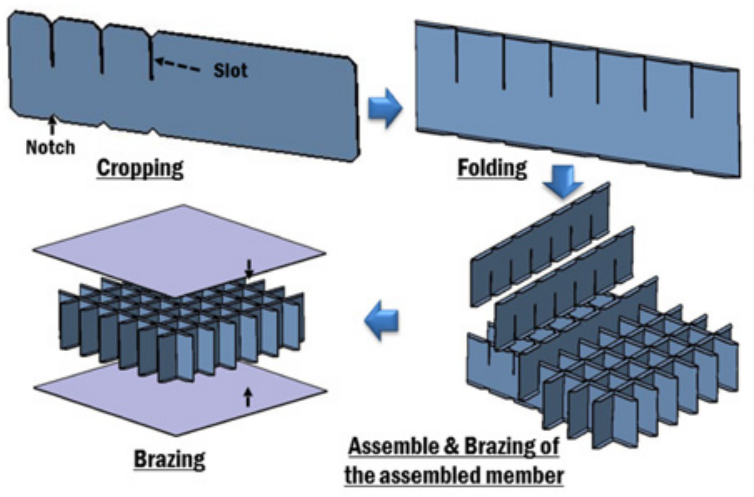

(a)

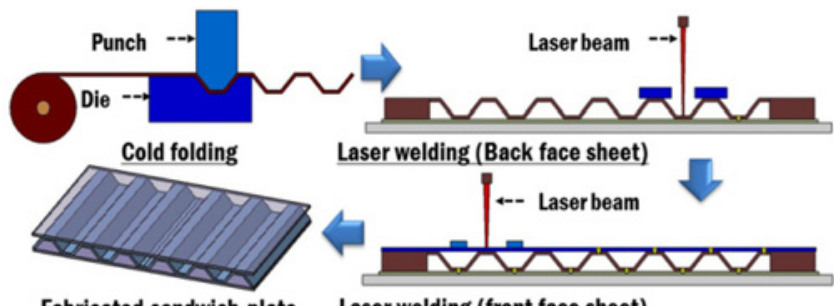

Fabricated sandwich plate Laser welding (front face sheet)

(b)

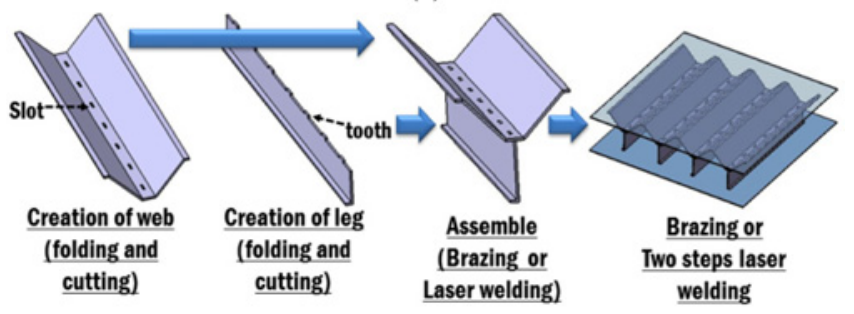

(c)

Fig. 7 Schematics of manufacturing processes for several thick metallic sandwich plates with square honeycomb, trapezoidal corrugated and Y-frame inner structures; (a) Metallic sandwich plates with square honeycomb PRMIS ${ }^{85}$ (adapted from Ref. 85), (b) Metallic sandwich plates with trapezoidal corrugated PRMIS ${ }^{58}$ (adapted from Ref. 58) (c) Metallic sandwich plates with Y-frame PRMIS ${ }^{56,86,89}$ (adapted from Refs. 56, 86 and 89)

created via a bending process using a die set. ${ }^{21,23,33,54,56,58,86}$ Rubino et al. employed a $\mathrm{CNC}$ folding process for the manufacture of 304 stainless steel corrugated inner structures. ${ }^{21,56,86}$ Zhang et al. fabricated trapezoidal corrugated inner structures with flat nodes from a continuous folding system, as shown in Fig. 7(b).$^{58}$ Brazing and laser welding processes were used to join the corrugated inner structures to the face sheets. ${ }^{21,23,33,54,56,58,86} \mathrm{Ni}-25 \mathrm{Cr}-10 \mathrm{P}, \mathrm{Ni}-22 \mathrm{Cr}-6 \mathrm{Si}$ and polymerbased cement were utilized in the brazing process. ${ }^{33,54,56,86}$ In the laser welding process, two laser welding steps were needed to weld the corrugated inner structures to front and back face sheets as shown in Fig. 7(b). ${ }^{23,58}$ Queheillalt et al. used an extrusion process to manufacture integrated aluminum sandwich plates with corrugated inner structures. ${ }^{40}$ Biagi et al. employed a friction stirring welding process for the expansion of the width of integrated aluminum sandwich plates. ${ }^{87,88}$

Rubion et al. developed the cold folding and assembly technique to manufacture Y-frame inner structures, as shown in Table 3 and Fig. $7(\mathrm{c}) .^{23,56,86,89}$ The webs and the legs of the Y-frame inner structures

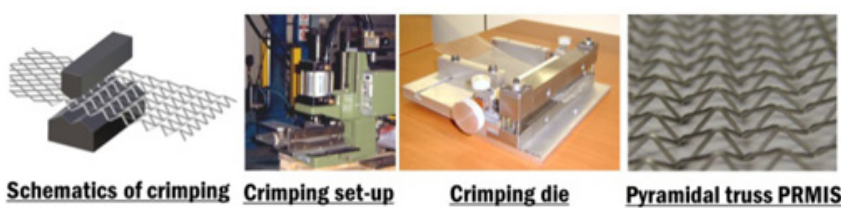

(a)

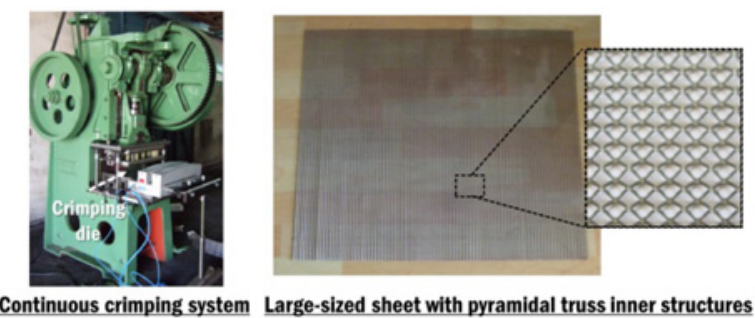

(b)

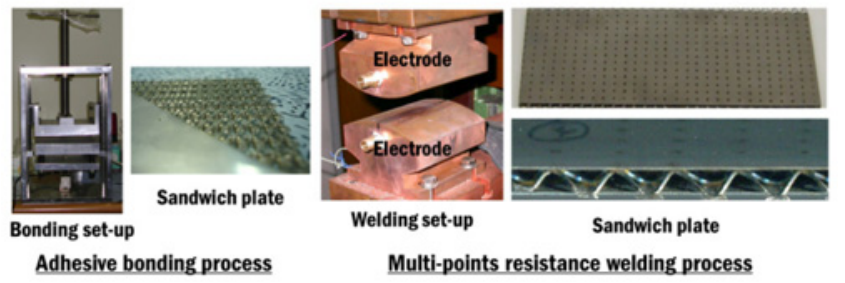

(c)

Fig. 8 Example of manufacturing processes of thin metallic sandwich plates with pyramidal truss inner structures; (a) Concept of crimping process of pyramidal truss PRMIS ${ }^{26,28,29,90}$ (adapted from Refs. 26, 28, 29 and 90 with permission of the Korean Society for Precision Engineering and the Korean Society of Mechanical Engineers) (b) Continuous crimping system of the thin metallic sandwich plate ${ }^{71,92}$ (adapted from Refs. 71 and 92 with permission of Prof. Dong-Yol Yang and Dr. Chang-Gyun Jung) (c) Joining process of the thin metallic sandwich plate ${ }^{29,36,90,91}$ (adapted from Refs. 29, 36, 90 and 91 with permission of the Korean Society for Precision Engineering and the Korean Society of Mechanical Engineers)

were fabricated from cold folding and $\mathrm{CNC}$ cutting processes. ${ }^{23,56,86,89}$ In order to create the web, the corrugated profile with flat nodes was manufactured from the cold folding process. ${ }^{23,56,86,89}$ Subsequently, slots were created using the $\mathrm{CNC}$ cutting process to assemble the web and the leg. ${ }^{23,56,86,89}$ The base shape of the legs was fabricated from the cold folding process. ${ }^{23,56,86,89}$ Subsequently, the teeth of the legs were generated by $\mathrm{CNC}$ cutting process to assemble the webs and the legs. ${ }^{23,56,86,89}$ Finally, the Y-frame inner structures were created by the assembly of the webs and the legs. ${ }^{23,56,86,89}$ Brazing and laser welding processes were employed for the assembly of the webs and the legs. ${ }^{23,56,86,89}$ Brazing and laser spot welding processes were adopted to join the Y-frame inner structures to the face sheets. ${ }^{23,56,86,89}$ In the brazing process, Ni-25Cr-10P braze material was used. ${ }^{56,89}$ In the laser spot welding process, a two-step approach was applied. ${ }^{23,86}$

\subsection{Thin Metallic Sandwich Plate}

Jung and Yang et al. proposed a novel manufacturing process for the fabrication of thin metallic sandwich plates with pyramidal truss inner structures, as shown in Table 3 and Fig. 8. ${ }^{26,28-30,36,65,71,90-92}$ They produced a rhombic-shaped metal mesh via the multiple slitting of the sheet metal and the expansion of the slit material. ${ }^{65,71,90,92}$ Pyramidal 
truss inner structures were manufactured from a continuous crimping process of the rhombic-shaped metal mesh, as shown in Fig. 8(b). ${ }^{26,28-}$ 30,36,65,71,90-92 They fabricated a large-sized sheet with pyramidal truss inner structures. ${ }^{71}$ The width of the large-sized sheet was $500 \mathrm{~mm}$, as shown in Fig. 8(b). ${ }^{71}$ They employed adhesive bonding and multipoints projection welding processes for joining of the pyramidal truss inner structures to the face sheets, as shown in Fig. 8(c). ${ }^{26,29,30,36,65,71,90,92}$

Yang et al. manufactured a thin metallic sandwich plate with woven wire inner structures, as shown in Table $3 .^{30,36,93-97}$ They utilized commercial metal woven wire as PRMIS..$^{30,36,93}$ The woven wire inner structures were joined to the face sheets using resistance brazing, adhesive bonding and multi-points projection welding processes. ${ }^{30,36,93-}$ ${ }^{97}$ They used a thick brazing foil, an epoxy and a curved surface block as a foil of the brazing process, an adhesive of the bonding process and an electrode of the welding process, respectively. ${ }^{30,36,93-97} \mathrm{Na}$ et al. reported that resistance brazing and adhesive bonding processes greatly increase the weight of thin metallic sandwich plates with pyramidal truss and woven wire inner structures to obtain the desired joining characteristics. $^{97}$ They examined the effects of parameters and conditions of the multi-points resistance welding process on the quality of the welded regions of metallic sandwich plates. ${ }^{94-97}$

In order to consider the effects of the variation of the dimension of thin metallic sandwich plate induced by the projection welding condition, Ahn et al. investigated into the influence of the crimping angle of the pyramidal truss inner structures on the weight and the bending performance of the thin metallic sandwich plates. ${ }^{65}$ The relative density of the thin metallic sandwich plates with $90^{\circ}$ crimping angle pyramidal truss inner structures ranged from 0.24 to $0.26{ }^{30}$ In addition, the relative density of the thin metallic sandwich plates with woven wire inner structures lies in the range of 0.37-0.41. ${ }^{30}$

Jung and Ahn et al. reported that the welding pressure gives rise to thickness reduction and initial imperfections of the metallic sandwich plates with pyramidal truss inner structures. ${ }^{26,66,91,92}$ They also demonstrated that thickness reduction and initial imperfections induced by the welding pressure should be considered to obtain the desired characteristics of the thin metallic sandwich plates. ${ }^{26,66,91,92}$ Lee et al. proposed a metallic sandwich plate with a trapezoidal folded pyramidal inner structures to improve joining characteristics between the inner structures and the face sheets. ${ }^{98}$

Seong and Yang et al. manufactured thin metallic dimple inner structures from a piecewise sectional forming process using a forming die, as shown in Table 3 and Fig. 9. ${ }^{63,64,67}$ The relative density of the unit cell of the dimple inner structures was nearly 0.21 . The multipoints resistance welding and adhesive bonding process using curved surface electrodes was adopted to join the dimple inner structures to the face sheets. ${ }^{26,64-67,91,92}$ Thickness deviation of the fabricated metallic sandwich plates was less than $7 \%{ }^{64}$ Seong et al. reported that the deflection of thin metallic sandwich plates with dimple inner structures at the point of the collapse is greatly increased as compared to that of pyramidal truss inner structures, while the thin metallic sandwich plates with dimple inner structures are nearly $10 \%$ heavier than the pyramidal truss inner structures. ${ }^{63,64}$

In order to mass-produce the thin metallic sandwich plate with a large area, Yang and $\mathrm{Na}$ et al. developed a continuous multi-points resistance welding process with 3-layer roll electrodes, as shown in Fig.

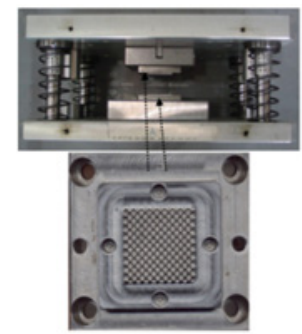

Dies for the sectional forming

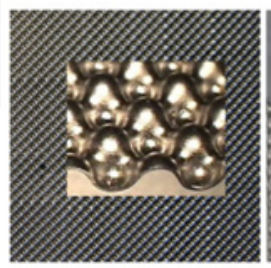

Dimple PRMIS

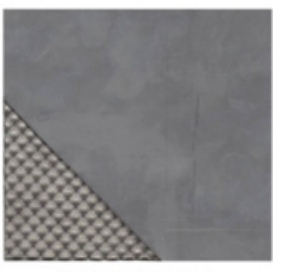

Sandwich plate
Fig. 9 Example of dies for dimple PRMIS and the thin metallic sandwich plate with dimple PRMIS ${ }^{63,64}$ (adapted from Refs. 63 and 64 with permission of Dr. Dae-Yong Seong and the Korean Society of Mechanical Engineers)

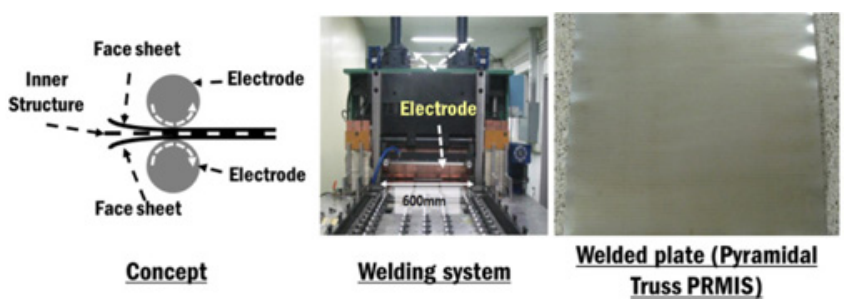

Fig. 10 Example of continuous multi-points resistance welding process $^{71,99}$ (adapted from Refs. 71 and 99 with permission of Prof. Dong-Yol Yang and the Korean Society of Mechanical Engineers)

$10 .^{61,62,66,70-72,91,97,99}$ The continuous multi-points resistance welding process was applied to metallic sandwich plates with pyramidal truss and sheared dimple inner structures. ${ }^{61,62,66,70-72,91}$ They examined the influence of welding parameters, including the dynamic resistance, the skin temperature, the feeding speed, and the gap between roll electrodes, on the quality, such as the microstructure, the peel strength and the welded mark, of the welded region. ${ }^{66,71,97}$ They employed infrared temperature sensors for measuring of the skin temperature of the metallic sandwich plate during the continuous welding process. ${ }^{71,97}$ They showed that the proper reduction ratio for the thickness of the metallic sandwich plates with pyramidal truss and sheared dimple inner structures are approximately $7 \%$ and $5 \%$, respectively. ${ }^{66,97}$

Seong and Yang et al. manufactured thin metallic sheared dimple inner structures from continuous sectional forming using a die set and rolling forming using a roll type of die, as shown in Table 3 and Fig. 11. ${ }^{61,62,70-72,99}$ The relative density of the unit cell of the sheared dimple inner structure was approximately $0.28 .^{62}$ They manufactured a large sized sheet with metallic dimple inner structures, as shown in Fig. 11(a). ${ }^{71,72}$ The width and the length of the large sized sheet with metallic dimple inner structures were $500 \mathrm{~mm}$ and $2,500 \mathrm{~mm}$, respectively. ${ }^{71,72}$ Continuous multi-points resistance welding, multipoints resistance welding and brazing processes were adopted to join the dimple inner structures to the face sheets. ${ }^{61,62,68,70-72,97,99}$ They used a nickel-based filler material for the brazing process. ${ }^{68,70-72}$ They described the detailed conditions of brazing and welding processes. 68,70-72 Seong et al. researched the out-of-plane deformation characteristics of thin metallic sandwich plates with sheared dimple inner structures to improve formability and de-bonding resistance of thin metallic sandwich plates. ${ }^{61,62,68,70-72,99}$ They investigated into the influence of the joining technique on the stress-strain relationship of the face sheets. $^{70,72}$ They demonstrated that the tensile strength and the 


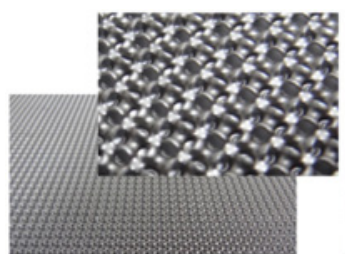

Sheared dimple PRMIS

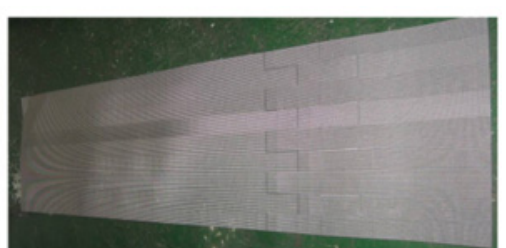

Large-sized sheet with sheared dimple PRMIS

(a)

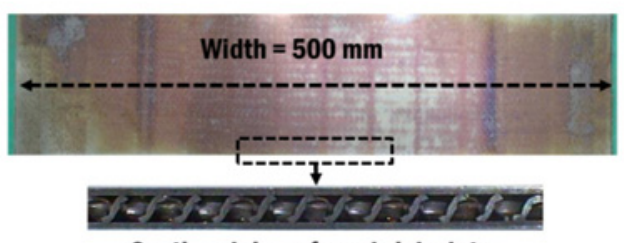

Sectional view of sandwich plate

(b)

Fig. 11 Example of thin metallic sandwich plates with sheared dimple inner structures; (a) Sheared dimple PRMIS and large-sized sheet ${ }^{71,72}$ (adapted from Refs. 71 and 72 with permission of Prof. Dong-Yol Yang, Dr. Dae-Yong Seong) (b) Large-Sized metallic sandwich plate with sheared dimple PRMIS ${ }^{72}$ (adapted from Ref. 72 with permission of Prof. Dong-Yol Yang)
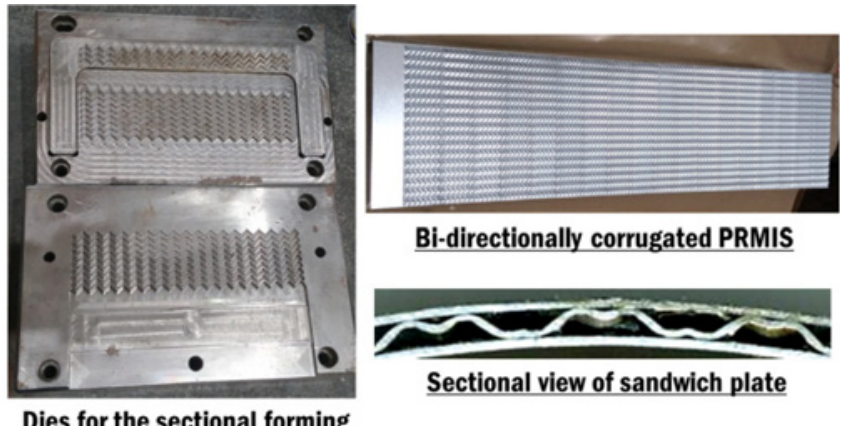

Bi-directionally corrugated PRMIS

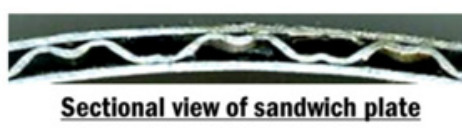

Fig. 12 Examples of dies and sheets of bi-directionally corrugated inner structures as well as thin metallic sandwich plate with bidirectionally corrugated inner structures (adapted from figures provided by Prof. Dong-Yol Yang and Dr. Dae-Yong Seong with permission)

maximum elongation of the welded face sheet decreased by $13.3 \%$ and $22.7 \%$ as compared to those of the initial face sheets, while the yield strength of the welded face sheets increased by $26.0 \%$ as compared to that of the initial face sheets. ${ }^{70,72}$ In addition, they reported that the yield strength and the tensile strength of the brazed face sheet decreased by $29.5 \%$ and $39.8 \%$ as compared to those of the initial face sheet, while the maximum elongation of the brazed face sheet is nearly identical to that of the initial face sheet. ${ }^{70,72}$ They examined the effects of the joining technique on the forming condition of thin metallic sandwich plates with sheared dimple inner structures. ${ }^{61,68,71,72}$ Ahn et al. reported that the welding pressure and the welding heat of the continuous multi-points resistance welding process create initial imperfections with the deformation of the sheared dimple inner structures. In addition, they demonstrated that initial imperfections affect the behavior and the failure of the metallic sandwich plates. ${ }^{99}$

Seong and Yang et al. manufactured bi-directionally corrugated

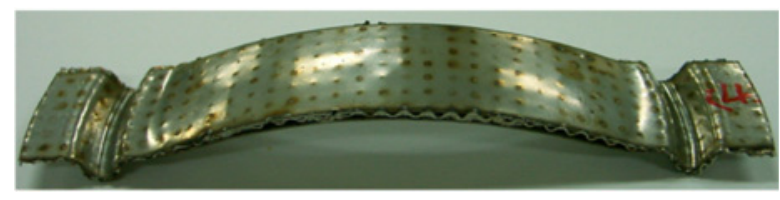

Fig. 13 Example of the stretch formed thin metallic sandwich plate with dimple inner structures (reprinted from figure provided by Prof. Dong-Yol Yang, Prof. Jong-Ho Kim and Dr. Dae-Yong Seong with permission)

inner structures from a sectional forming process using dies, as shown in Table 3 and Fig. 12. ${ }^{69,100}$ The relative density of the unit inner structure was $0.22 .{ }^{69}$ An adhesive bonding process was used to join the bi-directionally corrugated inner structures to the face sheets. The adhesive epoxy with YD-128 (60 wt \%) and KR208 (40 wt \%) was chosen as the adhesive. ${ }^{69}$ The detailed techniques of the adhesive bonding process were described in Ref. 69. They demonstrated that the bending response and the formability of metallic sandwich plates with bi-directionally corrugated inner structures are hardly influenced by the orientation of the inner structures. ${ }^{69}$

\section{Formability of Metallic Sandwich Plates with Single Layer PRMIS}

The investigation of the formability of metallic sandwich plates is needed to apply metallic sandwich plates with PRMIS to industrial components with desired shapes.

Dilthey et al. examined bending characteristics of thick metallic sandwich plates with woven wire inner structures to fabricate quarterring with diameters of $800 \mathrm{~mm} .{ }^{47}$ The influence of the geometry of the die and the punch on the spring-back of the quarter-ring was investigated using bending experiments at the forming temperature of $600^{\circ} \mathrm{C}^{47}$ They attempted to apply the formed thick metallic sandwich plate with woven wire inner structures to a turbine case and a rotor surface of a steam turbine. ${ }^{47}$

Mohr studied the formability of thin metallic sandwich plates with perforated inner structures using draw bending experiments and analyses. ${ }^{59}$ The face sheets and the inner structures were made from 304 stainless steel with a thickness of $0.2 \mathrm{~mm}$ and C1018 low carbon steel with a thickness of $1.6 \mathrm{~mm}$, respectively. ${ }^{59}$ The face sheets were brazed on to the inner structures using copper. ${ }^{59} \mathrm{He}$ demonstrated that the formability of thin metallic sandwich plates is influenced by the shear strength of the inner structures. ${ }^{59} \mathrm{He}$ developed the design map to estimate the required sheared strength of the inner structures for different properties of the face sheets, thicknesses of the inner structures and radii of the dies. ${ }^{59}$

Yang and Kim et al. investigated into the formability of thin metallic sandwich plates with pyramidal truss inner structures using $\mathrm{L}$ bending, $\mathrm{U}$ bending, hydroforming, and drawing experiments. ${ }^{71,72,101}$ They reported that thin metallic sandwich plates with pyramidal truss inner structures can be applicable to the product with a shallow drawing depth and a small curvature. ${ }^{71,72}$ The minimum radius of curvature of the die for thin metallic sandwich plates with pyramidal inner structures exceeded $1,000 \mathrm{~mm}$. In order to examine the variation of deformation 


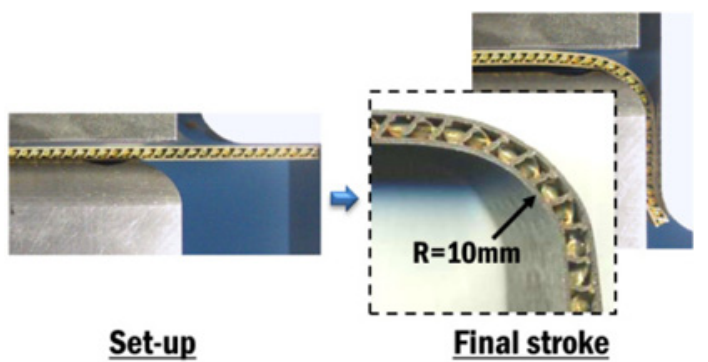

Fig. 14 Example of bended thin metallic sandwich plates with sheared dimple inner structures using the U-bending experiment ${ }^{71}$ (adapted from Ref. 71 with permission of Prof. Dong-Yol Yang and Prof. Jong-Ho Kim)

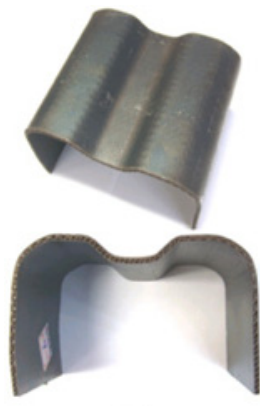

(a)

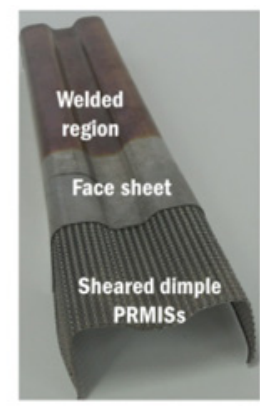

(b)

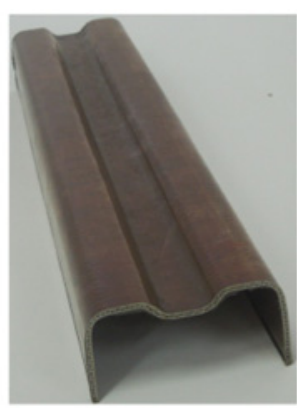

Fig. 15 Examples of the fabricated the bumper back beam section using thin metallic sandwich plates with sheared dimple inner structures; (a) Fabricated bumper back beam sections using a multistep forming process ${ }^{71}$ (adapted from Ref. 71 with permission of Prof. Dong-Yol Yang and Prof. Jong-Ho Kim) (b) Fabricated bumper back beam sections using a multi-step roll forming process

and failure characteristics of thin metallic sandwich plates according to $\mathrm{U}$ bending conditions, Seong et al. developed an efficient prediction methodology for local failure of thin metallic sandwich plates with pyramidal truss inner structures during the $\mathrm{U}$ bending process. ${ }^{71,72,102}$ They also created forming windows of bendable metallic sandwich plates with pyramidal truss inner structures. ${ }^{72,102}$ Chung et al. examined bending characteristics of metallic sandwich plates with pyramidal truss inner structures using non-linear finite element analysis considering an equivalent model. ${ }^{71,101}$

Seong and Kim et al. examined the formability of thin metallic sandwich plates with dimple inner structures through static three-points bending, stretch forming and incremental forming experiments, as shown in Fig. 12. ${ }^{64,67,71}$ They demonstrated that thin metallic sandwich plates with dimple inner structures can be applicable to a forming processes for products with a radius of curvature of $330 \mathrm{~mm} .{ }^{67}$ The forming depth of metallic sandwich plates with dimple inner structures was greatly deeper than that of metallic sandwich plates with pyramidal inner structures. ${ }^{64,67}$ Seong and Kim et al. revealed that the thickness deviation and the surface roughness of the deformed metallic sandwich plate with dimple inner structures are influenced by intervals of the weld regions. Fig. 13 showed the example of the stretch formed thin metallic sandwich plate with dimple inner structures.

Seong and Kim et al. investigated into the effects of the radius and the clearance of the dies on bending characteristics of brazed metallic sandwich plates with sheared dimple inner structures, as shown in Fig.
$14{ }^{68,71,72}$ They reported that brazed metallic sandwich plates with sheared dimple inner structures can be successfully formed without any failure when the radius of the die, the clearance of the die and the relative bending radius are $10 \mathrm{~mm}, 3.3 \mathrm{~mm}$ and 3.33 , respectively. ${ }^{68,71,72}$ Seong et al. developed the relationship between the normalized maximum shear stress of the core and the normalized clearance of the dies to prevent de-bonding failure during U-bending of metallic sandwich plates with sheared dimple inner structures welded by the continuous multi-points resistance welding process. ${ }^{61,71,72}$ They demonstrated that welded metallic sandwich plates with sheared dimple inner structures can be successfully formed without any failure when the radius of the die, and the clearance of the die are $10 \mathrm{~mm}$ and 9.0 $\mathrm{mm}$, respectively. ${ }^{61,71,72}$ They proposed a multi-step forming process, consisting of three forming steps, and the conditions of each forming step to create a cross-section of a front bumper back beam using welded metallic sandwich plates with sheared dimple inner structures. ${ }^{61,71,72}$ Yang et al. performed rectangular drawing experiments. ${ }^{71}$ Chung et al. examined bending characteristics of metallic sandwich plates with sheared dimple inner structures using non-linear finite element analysis considering an equivalent model. ${ }^{71}$ Yang and Lee et al. applied welded metallic sandwich plates with sheared dimple inner structures to a front bumper back beam. ${ }^{71}$ They used multi-step roll forming and stretch bending processes to manufacture a front bumper back beam by applying the welded metallic sandwich plates. ${ }^{71}$ Fig. 15 shows the fabricated the bumper back beam sections via multi-step forming and multi-step roll forming processes.

Seong and Kim et al. studied the formability of thin metallic sandwich plates with bi-directionally corrugated inner structures via draw bending, stretch forming, U-bending, and L-bending experiments. ${ }^{69,100}$ They examined the maximum punch stroke without failure of metallic sandwich plates with the bi-directionally corrugated inner structures. ${ }^{69,100}$ They found that the drawing process is more suitable to the stretching process when metallic sandwich plates with the bi-directionally corrugated inner structures are formed by the metal forming process. ${ }^{100}$ Seong et al. investigated into the deformation behavior of metallic sandwich plates with bi-directionally corrugated inner structures using the bending experiment. ${ }^{69}$ They demonstrated that the spring back and the minimum bendable radius of curvature of metallic sandwich plates with bi-directionally corrugated inner structures are $8.9 \%$ of the punch stroke and $12.7 \mathrm{~mm}$, respectively. ${ }^{69}$

\section{Summary and Future Issues}

This paper reviewed recent research trends and the state of the art of metallic sandwich plates with single layer PRMIS.

The concept of metallic sandwich plates with PRMIS, the design of PRMIS and the material of metallic sandwich plates were described. The design of thick metallic sandwich plates with PRMIS was focused on the reduction of the relative density and the improvement of the structural performance. Several researchers contrived to the folded PRMIS to improve joining characteristics between the face sheets and the inner structures. Thin metallic sandwich plates with PRMIS were designed to improve deformation characteristics and the formability of 
Table 4 Future Issues

- Inner structures with a low relative density and multifunctionality

- Metallic sandwich plates with multi-functionality

Design

- Deformable inner structures and deformable metallic sandwich plates with a low relative density

- Inner structures to improve joining characteristics

- Effective continuous manufacturing technologies of inner structures for mass-production

- Effective continuous joining technologies of metallic

sandwich plates with inner structures for mass-production

Manufacturing - Estimation of dominant imperfection modes induced by joining process for different inner structures

- Process control technology to prevent the initial imperfection of the metallic sandwich plate

- Evaluation technology of quality for the manufactured metallic sandwich plates

- Design map of inner structures and metallic sandwich plates for the metal forming of metallic sandwich plate

- Proper forming technologies for different metallic sandwich plates

Forming

- Investigation of the influence of process parameters on the formability of metallic sandwich plates

- Practical forming technology to fabricate commercial product using the metallic sandwich plates

metallic sandwich plates. Several designs of the PRMIS could solve the problem of anisotropy of the metallic sandwich plates.

Key manufacturing technologies for metallic sandwich plates with PRMIS were discussed. Various manufacturing technologies were adopted to fabricate PRMIS for thick metallic sandwich plates. Most of developed manufacturing technologies of PRMIS for thick metallic sandwich plates used metal forming, cutting and joining processes. Woven wire and Kagome inner structures were generally fabricated from weaving of stainless steel wires. In addition, continuous manufacturing technologies, including multi-step metal forming, joining and cutting processes, were developed to improve the productivity of pyramidal truss, tetrahedral truss, Kagome, honeycomb, and corrugated inner structures. Adhesive bonding, brazing, TLP bonding, laser spot welding, and CDR welding processes were used to join the PRMIS to the face sheets. In order to create integrated thick metallic sandwich plates with PRMIS, investment casting and extrusion assisted manufacturing technologies were developed. A porosity problem occurred in metallic sandwich plates fabricated from the investment casting assisted manufacturing technology. PRMIS for thin metallic sandwich plates were fabricated from metal forming assisted manufacturing technologies, excluding the woven wire inner structures. Continuous manufacturing technologies were developed to massproduce large-sized pyramidal truss and sheared dimple inner structures. Commercial woven wires were used as inner structures of the thin metallic sandwich plates. Adhesive bonding, multi-points resistance welding and brazing processes were adopted to join the PRMIS of thin metallic sandwich plates to the face sheets. In addition, the continuous multi-points resistance welding process was developed to mass-produce large-sized thin metallic sandwich plates.

The state of the art related on the forming technology and the formability of metallic sandwich plates with PRMIS was studied. Research works related to the forming technology and the formability of metallic sandwich plates were almost entirely concentrated on thin metallic sandwich plates. The formability of thin metallic sandwich plates was greatly influenced by the shear strength of the PRMIS. The forming conditions of thin metallic sandwich plates were estimated via fundamental metal forming processes. Metal forming technologies were developed to fabricate bumper back beam sections using thin deformable metallic sandwich plates. From the results of the investigation of the forming technology and the formability of metallic sandwich plates, it was considered that thin deformable metallic sandwich plates can improve the formability of metallic sandwich plates.

Through this critical review of the key technologies and the state of the art of metallic sandwich plates with PRMIS, several future research issues were identified from the viewpoint of the design, the manufacturing technology and the forming technology of metallic sandwich plates with PRMIS, as shown in Table 4.

\section{ACKNOWLEDGEMENT}

Author is deeply grateful to Prof. Dong-Yol Yang, Dr. Chang-Gyun Jung, Dr. Dae-Yong Seong, and Prof. Jong-Ho Kim for their kindness.

\section{REFERENCES}

1. Hoel, M. and Kverndokk, S., "Depletion of Fossil Fuels and the Impacts of Global Warming," Resource and Energy Economics, Vol. 18, No. 2, pp. 115-136, 1996.

2. Von Blottnitz, H. and Curran, M. A., "A Review of Assessments Conducted on Bio-Ethanol as a Transportation Fuel from a Net Energy, Greenhouse Gas, and Environmental Life Cycle Perspective," Journal of Cleaner Production, Vol. 15, No. 7, pp. $607-$ 619, 2007.

3. Chon, W. T., Poh, S. C., Fazlizan, A., Yip, S. Y., Koay, M. H., et al., "Exhaust Air Energy Recovery System for Electrical Power Generation in Future Green Cities,” Int. J. Precis. Eng. Manuf., Vol. 14, No. 6, pp. 1029-1035, 2013.

4. Kuo, T. C., Chen, H. M., Liu, C. Y., Tu, J. C., and Yeh, T. C., "Applying Multi-Objective Planning in Low-Carbon Product Design,” Int. J. Precis. Eng. Manuf., Vol. 15, No. 2, pp. 241-249, 2014.

5. Jeong, J., Lee, D., Kim, N., Zheng, C., Park, Y. I., and Cha, S. W., "Development of PMP-Based Power Management Strategy for a Parallel Hybrid Electric Bus,” Int. J. Precis. Eng. Manuf., Vol. 15, No. 2, pp. 345-353, 2014.

6. Jeong, M. G., Jin, C. K., Hwang, G. W., and Kang, C. G., "Formability Evaluation of Stainless Steel Bipolar Plate Considering Draft Angle of Die and Process Parameters by Rubber Forming," Int. J. Precis. Eng. Manuf., Vol. 15, No. 5, pp. 913-919, 2014.

7. Kanahashi, H., Mukai, T., Yamada, Y., Shimojima, K., Mabuchi, M., et al., "Experimental Study for the Improvement of Crashworthiness 
in AZ91 Magnesium Foam Controlling Its Microstructure," Materials Science and Engineering: A, Vol. 308, No. 1-2, pp. 283287, 2001

8. Karbasian, H. and Tekkaya, A. E., "A Review on Hot Stamping," Journal of Materials Processing Technology, Vol. 210, No. 15, pp. 2103-2118, 2010.

9. Nakjima, K., Utsumi, N., and Yoshida, M., "Suppressing Method of the Cross Section Deformation for Extruded Square Tubes in Press Bending," Int. J. Precis. Eng. Manuf., Vol. 14, No. 6, pp. 965-970, 2013.

10. Park, J. H. and Kim, K. J., "Optimal Design of Camber Link Component for Light Weight Automobile Using CAE (Computer Aided Engineering)," Int. J. Precis. Eng. Manuf., Vol. 14, No. 8, pp. 1433-1437, 2013.

11. Nguyen, T. T. and Park, H. S., "Optimization of Roll Forming Process with Evolutionary Algorithm for Green Product," Int. J. Precis. Eng. Manuf., Vol. 14, No. 12, pp. 2127-2135, 2013.

12. Kim, J. W. and Lee, D. G., "Study on the Fiber Orientation during Compression Molding of Reinforced Thermoplastic Composites," Int. J. Precis. Eng. Manuf.-Green Tech., Vol. 1, No. 4, pp. 335-339, 2014.

13. Lee, Y., Lee, S. I., and Yoon, J. H., "Effect of the Extrusion Ratio on the Mechanical Properties of As-Forged Mg-8Al-0.5Zn Alloy,” Int. J. Precis. Eng. Manuf.-Green Tech., Vol. 2, No. 3, pp. 275-280, 2015.

14. Furusako, S., Uenishi, A., and Miyazaki, Y., "Improvement of Crashworthiness by Application of High Strength," Journal of Society of Automotive Engineers of Japan, Vol. 55, No. 10, pp. 3639, 2001.

15. Andersson, R., Schedin, E., Magnusson, C., Ocklund, J., and Persson, A., "The Applicability of Stainless Steel for Crash Absorbing Components," SAE Technical Paper, Vol. 111, No. 6, pp. 1918-1922, 2002.

16. Ahn, D. G., Moon, G. J., Jung, C. G., Han, G. Y., and Yang, D. Y., "Impact Behavior of a STS $304 \mathrm{H}$ Sheet with a Thickness of 0.7 mm," Arabian Journal of Science and Engineering, Vol. 34, No. 1C, pp. 57-71, 2009.

17. Evans, A. G., Hutchinson, J. W., Fleck, N. A., Ashby, M. F., and Wadley, H. N. G, "The Topological Design of Multifunctional Cellular Metals," Progress in Materials Science, Vol. 46, No. 3-4, pp. 309-327, 2001.

18. Gibson, L. J. and Ashby, M. F., "Cellular Solids, Structure and Properties," Cambridge University Press, $2^{\text {nd }}$ Ed., 2001.

19. Sypeck, D. J. and Wadley, H. N. G., "Cellular Metal Truss Core Sandwich Structures," Advanced Engineering Materials, Vol. 4, No. 10, pp. 759-764, 2002.

20. Sypeck, D. J., "Cellular Truss Core Sandwich Structures," Applied Composite Materials, Vol. 12, No. 3-4, pp. 229-246, 2005.

21. Wadley, H. N. G., "Multifunctional Periodic Cellular Metals," Philosophical Transactions of the Royal Society of London A:
Mathematical, Physical and Engineering Sciences, Vol. 364, No. 1838, pp. 31-68, 2006.

22. Côtê, F., Deshpande, V. S., Fleck, N. A., and Evans, A. G., "The Compressive and Shear Responses of Corrugated and Diamond Lattice Materials," International Journal of Solids and Structures, Vol. 43, No. 20, pp. 6220-6242, 2006.

23. Rubino, V., Deshpande, V. S., and Fleck, N. A., "The Dynamic Response of Clamped Rectangular Y-Frame and Corrugated Core Sandwich Plates," European Journal of Mechanics-A/Solids, Vol. 28, No. 1, pp. 14-24, 2009.

24. Nguyen, J., Park, S. I., and Rosen, D., "Heuristic Optimization Method for Cellular Structure Design of Light Weight Components," Int. J. Precis. Eng. Manuf., Vol. 14, No. 6, pp. 1071-1078, 2013.

25. Choi, J., Shankar, K., Choi, B. B., and Lee, J. H., "In-Plane Shear Behavior of Corrugated Cellular Solids and Validation of an OpenCell Corrugated Cellular Solid,” Int. J. Precis. Eng. Manuf., Vol. 14, No. 10, pp. 1767-1774, 2013.

26. Ahn, D. G. and Sun, H. S., "Dynamic Failure Characteristics of Metallic Sandwich Plate with Repeated Metallic Truss Cores Subjected to a Plane Strain Drop Impact Condition,” Int. J. Precis. Eng. Manuf.-Green Tech., Vol. 1, No. 1, pp. 31-34, 2014.

27. Kang, K. J, "Wire-Woven Cellular Metals: The Present and Future," Progress in Materials Science, Vol. 69, pp. 213-307, 2015.

28. Jung, C. G., Yoon, S. J., Sung, D. Y., Yang, D. Y., and Ahn, D. G., "Fabrication and Static Bending Test in Ultra Light Inner Structured and Bonded(ISB) Panel Containing Repeated Inner Pyramidal Structure,” Proc. of KSPE Autumn Conference, pp. 247-250, 2004.

29. Ahn, D. G., Moon, G. J., Jung, C. G., and Yang, D. Y., "Variation of Impact Characteristics of ISB Panels with a Pyramidal Inner Structure according to Joining Technologies,” J. Korean Soc. Precis. Eng., Vol. 24, No. 9, pp. 110-118, 2007.

30. Ahn, D. G., Lee, S. H., Kim, M. S., Han, G. Y., Jung, C. G., et al., "Investigation into Characteristics of Bending Stiffness and Failure for ISB Panel,” J. Korean Soc. Precis. Eng., Vol. 22, No. 9, pp. 162-172, 2005.

31. Wicks, N. and Hutchinson, J. W., "Performance of Sandwich Plates with Truss Cores," Mechanics of Materials, Vol. 36, No. 8, pp. 739-751, 2004.

32. Côtê, F., Deshpande, V. S., Fleck, N. A., and Evans, A. G., "The Out-of-Plane Compressive Behavior of Metallic Honeycombs," Materials Science and Engineering: A, Vol. 380, No. 1-2, pp. 272280, 2004

33. Radford, D. D., Fleck, N. A., and Deshpande, V. S., "The Response of Clamped Sandwich Beams Subjected to Shock Loading," International Journal of Impact Engineering, Vol. 32, No. 6, pp. 968-987, 2006.

34. Allen, H. G., "Analysis and Design of Structural Sandwich Panels," Pergamon Press, 1969.

35. Ahn, D. G., Nam, G. H., Jung, C. G., and Yang, D. Y., "Estimation of Young's and Shear Moduli of a Core in ISB Panel with Woven 
Metal as Inner Structures,” J. Korean Soc. Precis. Eng., Vol. 26, No. 11, pp. 116-123, 2009.

36. Ahn, D. G., Nam, G. H., Jung, C. G., and Yang, D. Y., "Experimental Determination of Elastic Properties of the Core in a Thin Sandwich Plate with a Metallic Truss Core,” Int. J. Precis. Eng. Manuf., Vol. 10, No. 5, pp. 107-113, 2009.

37. Wadley, H. N. G., Fleck, N. A., and Evans, A. G., "Fabrication and Structural Performance of Periodic Cellular Metal Sandwich Structures," Composites Science and Technology, Vol. 63, No. 16, pp. 2331-2343, 2003.

38. Kooistra, G. W. and Wadley, H. N. G., "Lattice Truss Structures from Expanded Metal Sheet," Materials and Design, Vol. 28, No. 2, pp. 507-514, 2007.

39. Biagi, R. and Bart-Smith, H., "Imperfection Sensitivity of Pyramidal Core Sandwich Structures," International Journal of Solids and Structures, Vol. 44, No. 14-15, pp. 4690-4706, 2007.

40. Queheillalt, D. T., Murty, Y., and Wadley, H. N., "Mechanical Properties of an Extruded Pyramidal Lattice Truss Sandwich Structure," Scripta Materialia, Vol. 58, No. 1, pp. 76-79, 2008.

41. Chiras, S., Mumm, D. R., Evans, A. G., Wicks, N., Hutchinson, J. W., et al., "The Structural Performance of Near-Optimized Truss Core Panels," International Journal of Solids and Structures, Vol. 39, No. 15, pp. 4093-4115, 2002.

42. Sugimura, Y., "Mechanical Response of Single-Layer Tetrahedral Trusses under Shear Loading," Mechanics of Materials, Vol. 36, No. 8, pp. 715-721, 2004.

43. Kooistra, G. W., Deshpande, V. S., and Wadley, H. N. G., "Compressive Behavior of Age Hardenable Tetrahedral Lattice Truss Structures Made from Aluminum," Acta Materialia, Vol. 52, No. 14, pp. 4229-4237, 2004.

44. Wang, J., Evans, A. G., Dharmasena, K., and Wadley, H. N. G., "On the Performance of Truss Panels with Kagomê Cores," International Journal of Solids and Structures, Vol. 40, No. 25, pp. 6981-6988, 2003.

45. Lim, J. H. and Kang, K. J., "Mechanical Behavior of Sandwich Panels with Tetrahedral and Kagome Truss Cores Fabricated from Wires," International Journal of Solids and Structures, Vol. 43, No. 17, pp. 5228-5246, 2006.

46. Lee, Y. H. and Kang, K. J., "A Wire-Woven Cellular Metal: Part-I, Optimal Design for Applications as Sandwich Core," Materials and Design, Vol. 30, No. 10, pp. 4434-4443, 2009.

47. Dilthey, U., Ghandehari, A., Kopp, R., Hohmeier, P., Beiss, P., et al., "Development of Porous Steel Structures for Steam Turbines," Advanced Engineering Materials, Vol. 3, No. 3, pp. 111-119, 2001.

48. Speck, D. J. and Wadely, H. N. G., "Multifunctional Microtruss Laminates: Textile Synthesis and Properties," Journal of Materials Research, Vol. 16, No. 3, pp. 890-897, 2001.
49. Zupan, M., Deshpande, V. S., and Fleck, N. A., "The Out-of-Plane Compressive Behaviour of Woven-Wire Core Sandwich Plates," European Journal of Mechanics-A/Solids, Vol. 23, No. 3, pp. 411421, 2004

50. Silva, M. J., Hayes, W. C., and Gibson, L. J., "The Effects of NonPeriodic Microstructure on the Elastic Properties of TwoDimensional Cellular Solids," International Journal of Mechanical Sciences, Vol. 37, No. 11, pp. 1161-1177, 1995.

51. Xue, Z. and Hutchinson, J. W., "A Comparative Study of ImpulseResistant Metal Sandwich Plate," International Journal of Impact Engineering, Vol. 30, No. 10, pp. 1283-1305, 2004.

52. Rathbun, H. J., Radford, D. D., Xue, Z., He, M. Y., Yang, J., et al., "Performance of Metallic Honeycomb-Core Sandwich Beam under Shock Loading," International Journal of Solids and Structures, Vol. 43, No. 6, pp. 1746-1763, 2006.

53. Vaziri, A., Xue, Z., and Hutchinson, J. W., "Performance and Failure of Metal Sandwich Plates Subjected to Shock Loading," Journal of Mechanics of Materials and Structures, Vol. 2, No. 10, pp. 19471963, 2007.

54. Valdevit, L., Wei, Z., Mercer, C., Zok, F. W., and Evans, A. G., "Structural Performance of Near-Optimal Sandwich Panels with Corrugated Cores," International Journal of Solids and Structures, Vol. 43, No. 16, pp. 4888-4905, 2006.

55. Magnuchki, K., Jasion, P., Krus, M., Kuligowski, P., and Wittenbeck, L., "Strength and Buckling of Sandwich Beams with Corrugated Core," Journal of Theoretical and Applied Mechanics, Vol. 51, No. 1, pp. 15-24, 2013.

56. Trilbrook, M. T., Radford, D. D., Deshpande, V. S., and Fleck, N. A., "Dynamic Crushing of Sandwich Planes with Prismatic Lattice Core," International Journal of Solids and Structures,, Vol. 44, No. 18-19, pp. 6101-6123, 2007.

57. Rubion, V., Deshpande, V. S., and Fleck, N. A., "The Dynamic Response of End-Clamped Sandwich Beams with Y-Frame or Corrugated Core," International Journal of Impact Engineering, Vol. 35, No. 8, pp. 829-844, 2008.

58. Zhang, P., Liu, J., Cheng, Y., Hou, Hailiang, Wang, C., et al., "Dynamic Response of Metallic Trapezoidal Corrugated-Core Sandwich Panels Subjected to Air Blast Loading-An Experimental Study," Materials and Design, Vol. 65, pp. 221-230, 2015.

59. Mohr, D., "On the Role of Shear Strength in Sandwich Sheet Forming," International Journal of Solids and Structures, Vol. 42, No. 5-6, pp. 1491-1512, 2005.

60. Metawell, "Aluminium-Sandwichplatten Überzeugen Im Leichtbau," http://www.metawell.de (Accessed 16 September 2015)

61. Seong, D. Y., Jung, C. G., Yang, D. Y., Ahn, J., Na, S. J, et al., "Analysis of Core Stress in Welded Deformable Sandwich Plates to Prevent De-Bonding Failure during U-Bending," Journal of Materials Processing Technology, Vol. 210, No. 9, pp. 1171-1179, 2010. 
62. Ahn, D. G., Nam, G. H., Seong, D. Y., Han, G. Y., and Yang, D. Y., "Low-Velocity Impact Response of a Thin Sandwich Plate with a Metallic Sheared Dimple Core Subjected to a Free Boundary Condition," Materials Science and Engineering: A, Vol. 210, No. 9, pp. 1171-1179, 2010.

63. Seong, D. Y., "Optimal Design of Metallic Sandwich Plates with Inner Dimple Shell Structure Subjected to Bending Moment," M.Sc. Thesis, Department of Mechanical Engineering, Korea Advanced Institute of Science Technology, 2005.

64. Seong, D. Y., Jung, C. G., Yoon, S. J., Yang, D. Y., Lee, S. H., et al., "Fabrication of Metallic Sandwich Plates with Inner Dimpled Shell Structures and Static Bending Test," Transactions of the Korean Society of Mechanical Engineers A, Vol. 30, No. 6, pp. 653-661, 2006.

65. Ahn, D. G., Lee, S. H., Jung, C. G., Hahn, G. Y., and Yang, D. Y., "Mechanical Properties and Failure Characteristics of ISB Panel with Metallic Pyramidal Inner Structures," Journal of Materials Processing Technology, Vol. 187-188, pp. 521-525, 2007.

66. Jung, C. G., Seong, D. Y., Yang, D. Y., Na, S. J., and Ahn, D. G., "Development of a Continuous Fabrication System for a Metallic Sandwich Plate with a Three-Dimensional Truss Core," The International Journal of Advanced Manufacturing Technology, Vol. 45, No. 3-4, pp. 352-361, 2009.

67. Seong, D. Y., Jung, C. G., Yang, D. Y., and Ahn, D. G., "Bending Behavior of Simply Supported Metallic Sandwich Plates with EggBox Cores," International Journal of Modern Physics B, Vol. 22, No. 31-32, pp. 6179-6184, 2008.

68. Seong, D. Y., Jung, C. G., Yang, D. Y., Kim, J. H., Chung, W. J., et al., "Bendable Metallic Sandwich Plates with a Sheared Dimple Core,” Scripta Materialia, Vol. 63, No. 1, pp. 81-84, 2010.

69. Seong, D. Y., Jung, C. G., Yang, D. Y., Moon, K. J., and Ahn, D. G., "Quasi-Isotropic Bending Responses of Metallic Sandwich Plates with Bi-Directionally Corrugated Cores," Materials and Design, Vol. 31, No. 6, pp. 2804-2812, 2010.

70. Seong, D. Y., Jung, C. G., Yang, D. Y., Nam, G. H., and Ahn, D. G., "Bending Behaviors of Metallic Sandwich Plates with a Sheared Dimple Core under Simply Supported Loading,” Journal of Sandwich Structures and Materials, Vol. 13, No. 4, pp. 445-466, 2011.

71. Yang, D. Y., Kim, B. H., Park, S. H., and Lee, M. Y., "Report on Industrial Technology Development Project - Development of Lightweight Metallic Sandwich Plate with Three-Dimensional Metallic Inner Structures," MOCIE in Korea, The Second Stage Report, 2008.

72. Seong, D. Y., "Investigation into Design of a Deformable Metallic Sandwich Plate," Ph.D. Thesis, Department of Mechanical Engineering, Korea Advanced Institute of Science Technology, 2010.

73. McShane, G. J., Radford, D. D., Deshpande, V. S., and Fleck, N. A., "The Response of Clamped Sandwich Plates with Lattice Cores Subjected to Shock Loading," European Journal of Mechanics-A/ Solids, Vol. 25, No. 2, pp. 215-229, 2006.
74. Zok, F. W., Waltner, S. A., Wei, Z., Rathbun, H. J., McMeeking, R. M., et al., "A Protocol for Characterizing the Structural Performance of Metallic Sandwich Panels: Application to Pyramidal Truss Cores," International Journal of Solids and Structures, Vol. 41, No. 22-23, pp. 6249-6271, 2004.

75. Cote, F., Biagi, R., Bart-Smith, H., and Deshpande, V. S., "Structural Response of Pyramidal Core Sandwich Columns," International Journal of Solids and Structures, Vol. 44, No. 10, pp. 3533-3556, 2007.

76. Yungwirth, C. J., Wadley, H. N. G., O’Connor, J. H., Zakraysek, A. J., and Deshpande, V. S., "Impact Response of Sandwich Plates with a Pyramidal Lattice Core," International Journal of Impact Engineering, Vol. 35, No. 8, pp. 920-936, 2008.

77. Lee, S., Barthelat, F., Hutchinson, J. W., and Espinosa, H. D., "Dynamic Failure of Metallic Pyramidal Truss Core MaterialsExperiments and Modeling," International Journal of Plasticity, Vol. 22, No. 1, pp. 2118-2145, 2006.

78. Deshpande, V. S. and Fleck, N. A., "Collapse of Truss Core Sandwich Beams in 3-Point Bending," International Journal of Solids and Structures Vol. 38, No. 36-37, pp. 6275-6305, 2001.

79. Kooistra, G. W., Queheillalt, D. T., and Wadely, H. N. G., "Shear Behavior of Aluminum Lattice Truss Sandwich Panel Structures," Materials Science and Engineering: A, Vol. 472, No. 1-2, pp. 242250, 2008.

80. Lee, Y. H., Lee, B. K., Jeon, I., and Kang, K. J., "Wire-Woven Bulk Kagome Truss Cores,” Acta Materialia, Vol. 55, No. 18, pp. 60846094, 2007.

81. Hyun, S., Choi, J. E., and Kang, K. J., "Mechanical Behaviors under Compression in Wire-Woven Bulk Kagome Truss PCMs (II)," Transactions of the Korean Society of Mechanical Engineers A, Vol. 31, No. 7, pp. 792-799, 2007.

82. Hyun, S., Choi, J. E., and Kang, K. J., "Effects of Imperfections on the Mechanical Behavior of a Wire-Woven Bulk Kagome Cellular Metal under Compression," Computational Materials Science, Vol. 46, No. 1, pp. 73-82, 2009.

83. Lim, C. H., Lim, J. H., Jung, J. G., Lim, J. D., and Kang, K. J., "Mechanical Behavior of Sandwich Panels with Quasi-Kagome Truss Core Fabricated from Expanded Metals," Transactions of the Korean Society of Mechanical Engineers A, Vol. 30, No. 9, pp. 1078-1085, 2006.

84. Bitzer, T., "Honeycomb Technology: Materials, Design, Manufacturing, Applications and Testing," Chapman and Hall, 1997.

85. Dharmasena, K. P., Wadley, H. N. G., Xue, Z., and Hutchinson, J. W, "Mechanical Response of Metallic Honeycomb Sandwich Panel Structures to High-Intensity Dynamic Loading," International Journal of Impact Engineering, Vol. 35, No. 9, pp. 1063-1074, 2008.

86. Rubino, V., Deshpande, V. S., and Fleck, N. A., "The Three-Point Bending of Y-Frame and Corrugated Core Sandwich Beams," 
International Journal of Mechanical Sciences, Vol. 52, No. 3, pp. 485-494, 2010.

87. Biagi, R., Lim, J. Y., and Bart-Smith, H., "In-Plane Compression Response of Extruded Aluminum 6061-T6 Corrugated Core Sandwich Columns," Journal of the American Ceramic Society, Vol. 94, No. Supplement 1, pp. S76-S84, 2011.

88. Lim, J. Y., Kim, J. S., Kim, J., and Bart-Smith, H., "Dynamic Effects on the Lightweight Design of Metallic Core Sandwich Columns," Journal of Mechanical Science and Technology, Vol. 29, No. 4, pp. 1335-1340, 2015.

89. Rubino, V., Deshpande, V. S., and Fleck, N. A., "The Collapse Response of Sandwich Beams with a Y-Frame Core Subjected to Distributed and Local Loading," International Journal of Mechanical Sciences, Vol. 50, No. 2, pp. 233-246, 2008.

90. Jung, C. G., Seong, D. Y., Yang, D. Y., Kim, J. S., and Ahn, D. G., "Low Velocity Impact Behavior of Metallic Sandwich Plate with a Truss Core,” J. Korean Soc. Precis. Eng., Vol. 23, No. 10, pp. 80-87, 2006.

91. Ahn, D. G. and Sun H. S., "Imperfection Mode of Thin Metallic Sandwich Plate with Pyramidal Metallic Inner Structures," Transactions of the Korean Society of Mechanical Engineers A, Vol. 37, No. 2, pp. 187-192, 2013.

92. Jung, C. G., "Design and Development of a Metallic Sandwich Plate with Truss Type 3-Dimensional Inner Structures," Ph.D. Thesis, Department of Mechanical Engineering, Korea Advanced Institute of Science Technology, 2009.

93. Jung, C. G., Yoon, S. J., Yang, D. Y., Lee, S. M., Na, S. J., et al., "Basic Study in Fabrication and Mechanical Characteristics of Ultra Light Inner Structured and Bonded(ISB) Panel Containing Perpendicularly Woven Metal,” J. Korean Soc. Precis. Eng., Vol. 22, No. 5, pp. 152-158, 2005.

94. Lee, S. M., Kim, J. B., and Na, S. J., "A Study on the Resistance Welding of Metallic Sandwich Panel: Part 1 - Determination of Process Parameters," Journal of Welding and Joining, Vol. 23, No. 6, pp. 545-550, 2005.

95. Lee, S. M., Kim, J. B., and Na, S. J., "A Study on the Resistance Welding of Metallic Sandwich Panel: Part 1 - Process Analysis," Journal of Welding and Joining, Vol. 23, No. 6, pp. 551-556, 2005.

96. Kim, J. B., Lee, S. M., and Na, S. J., "Study on Resistance Welding of Metallic Sandwich Panel," Science and Technology of Welding and Joining, Vol. 12, No. 5, pp. 376-380, 2007.

97. Na, S. J., Ahn, J., and Kim, J. H., "A Study on 3-Layer Roll Projection Welding of Large Area," Welding in the World, Vol. 53, No. 7-8, pp. 5-11, 2009.

98. Lee, S. H., Seong, D. Y., and Yang, D. Y., "Efficient Layered Manufacturing Method of Metallic Sandwich Panel with Pyramidal Truss Structures Using Infrared Brazing and Its Mechanical Characteristics,” J. Korean Soc. Precis. Eng., Vol. 27, No. 8, pp. 7683, 2010.
99. Ahn, D. G. and Jeong, W. C., "Failure Characteristics of a Thin Metallic Sandwich Plate with Metallic Sheared Dimple Cores under Low-Velocity Impact Loading," Journal of Mechanical Science and Technology, Vol. 27, No. 10, pp. 2941-2946, 2013.

100.Seong, D. Y., Jung, C. G., Shim, D. S., Yang, D. Y., Kim, J. Y., et al., "Fabrication and Forming of Metallic Sandwich Plates with BiDirectional Corrugated Inner Structure," Proc. of the Korean Society for Technology Plasticity Spring Conference, pp. 281-284, 2006.

101.Lim, S. J., Chung, W. J., and Kim, J. H., "Forming Analysis of LType Bending of Sandwich Sheet with Pyramid Core," Elastomers and Composites, Vol. 44, No. 4, pp. 378-383, 2009.

102.Seong, D. Y., Jung, C. G., Yang, D. Y., and Chung, W. J., "Efficient Prediction of Local Failures for Metallic Sandwich Plates with Pyramidal Truss Cores during the Bending Processes,” Int. J. Precis. Eng. Manuf., Vol. 12, No. 3, pp. 491-503, 2011. 